\title{
MANDATORY DISCLOSURE: THEORY AND EVIDENCE FROM INDUSTRY-PHYSICIAN RELATIONSHIPS
}

\author{
Daniel L. Chen, Vardges Levonyan, S. Eric Reinhart, Glen Taksler*
}

Abstract

The interaction of disclosure laws and the targeted behavior is typically unknown since data on disclosed activity rarely exist in the absence of disclosure laws. We exploit data from legal settlements disclosing $\$ 316$ million in pharmaceutical company payments to 316,622 physicians across the U.S. from 2009-2011. States were classified as having strong, weak, or no disclosure based on whether data were reported only to state authorities (weak) or were publicly available (strong). Strong disclosure law was associated with reduced payments among doctors accepting less than $\$ 100$ and increased payments among doctors accepting greater than $\$ 100$. Weak disclosure states, despite imposing administrative compliance costs to industry, were indistinguishable from no disclosure states. This result suggests that the primary mechanism for fewer small payments in strong disclosure states was physicians' reduced willingness to accept payments rather than the imposition of significant administrative costs on industry. We conduct additional analysis holding fixed the cost for pharmaceutical companies of disclosing data, which was possible because Massachusetts began releasing payment data online during our sample period. Differences-in-differences analyses and multiple regression yield similar estimates for each payment category: Mandatory disclosure reduced payments for speaking and for meals but increased payments for consulting activities. Differences-in-discontinuities in distribution of payments at the disclosure threshold among strong and weak disclosure states support the interpretation of physicians' reduced willingness to accept payments. Significant disclosure aversion reducing conflicts of interest is consistent with the policy goals of mandatory disclosure, though the increased payments among those receiving large payments may have been unintended.

Keywords: Physician Payment, Conflicts of Interest, Ethics

JEL: K23, I18

\footnotetext{
${ }^{*}$ Daniel L. Chen, daniel.chen@iast.fr, Toulouse School of Economics, Institute for Advanced Study in Toulouse, University of Toulouse Capitole, Toulouse, France; Vardges Levonyan, vlevonyan@ethz.ch, ETH Zurich; S. Eric Reinhart, ericreinhart@uchicago.edu, University of Chicago; Glen Taksler, glentaksler@gmail.com, Cleveland Clinic. First draft: April 2010. Current draft: February 2019. Most recent version at: http://nber.org/ dlchen/papers/Mandatory_Disclosure.pdf. We thank research assistants and numerous colleagues with helpful comments at the University of Pennsylvania, American Law and Economics Association, Physician-Scholars in the Social Sciences and Humanities, and Conference on Empirical Legal Studies. Work on this project was conducted while Chen received financial support from Alfred P. Sloan Foundation (Grant No. 2018-11245), European Research Council (Grant No. 614708), Swiss National Science Foundation (Grant Nos. 100018-152678 and 106014-150820), Agence Nationale de la Recherche, Ewing Marion Kauffman Foundation, and Templeton Foundation (Grant No. 22420).
} 


\section{INTRODUCTION}

The relationship between the pharmaceutical industry and the medical profession is the subject of heated debate in both the U.S. and Europe (see, e.g., Article 94 of European Parliament and Council Directive 200/83/EC on the Community code relating to medicinal products for human use, as amended; German Supreme Court decisions in the cases 3 StR 458/10, 4 StR 239/03, and 1 Str 165/03). In recent years, professional organizations have produced policy recommendations to limit contact between physicians and the pharmaceutical industry (see, e.g., Articles 9-14 of the European Federation of Pharmaceutical Industries and Associations (EFPIA) Code on the Promotion of Prescription-Only Medicines to, and Interactions with, Healthcare Professionals; and various publications of the World Health Organization (WHO), including "Understanding and Responding to Pharmaceutical Promotion: A Practical Guide," 2011, aimed at healthcare professionals). A large body of research recently summarized by the World Health Organization suggests that physicians may be influenced by financial conflicts of interest (Norris et al. 2005); recommendations limiting the size of transactions between physicians and pharmaceutical companies have been adopted by professional and industry groups.

Spending by the pharmaceutical industry on promotions and marketing in the U.S. grew from $\$ 11$ billion in 1996 to an estimated $\$ 29$ billion in 2011 (Donohue et al. 2007), with other independent estimates placing the number much higher (Donohue et al. 2007, IMS Health 2011, Kerber 2004, Wolfe, 1996, Gagnon and Lexchin 2008). Even accounting for direct-to-consumer advertising, $90 \%$ of promotional expenditures are directed towards physicians, amounting to between $\$ 30,000$ and $\$ 61,000$ per physician each year (Donohue et al. 2007). Although direct payments to physicians appear to constitute a relatively small proportion of these promotional expenditures, they are the subject of professional and political controversy. There is concern that these transactions may create conflicts of interest that undermine clinical objectivity and public trust in physician recommendations (Wazana 2000, Studdert et al. 2004, Chimonas et al. 2007, Campbell 2007). Moreover, industry-physician relationships have been linked to medical research, discovery, and promulgation of new drugs (Cockburn and Henderson 1998, Chatterji et al. 2008, Zinner et al. 2009).

The prevailing strategy for addressing potential conflicts of interest has been enhancement and 
enforcement of disclosure (Katz et al. 2003). This has been the case despite a lack of empirical evidence regarding the effects of disclosure on industry-physician financial relationships. Prior to federal legislation on disclosure in 2014, several states enacted "sunshine laws" that required companies to report payments to physicians (Brennan and Mello, 2007). In Massachusetts, Vermont, and Minnesota, these disclosures were public (Mass. Gen. Laws, ch. 111N, §6; Minn. Stat. $\S 151.461$; Vt. Stat. tit. 18, $\S \S 4631-2$.$) and since 2009, many pharmaceutical companies have pub-$ licly disclosed payment data for all 50 states (Merrill et al. 2013). Beginning in 2014, the Patient Protection and Affordable Care Act required disclosure of payments from pharmaceutical companies to physicians and the compilation of this data into a publicly searchable online database (42 C.F.R. $\S \S 402$ and 403).

Critics of disclosure suggest that these laws stigmatize physicians who maintain collaborative relationships with industry that are essential to innovation and product feedback (Sade 2011, Sigworth et al. 2001, Santhakumar and Adashi 2015). Some contend that disclosure may have the unintended consequences of moral licensing among physicians to conduct themselves in a biased manner and/or of producing greater public trust in physicians who have received larger payments (Cain et al. 2005, Loewenstein et al. 2012, Loewenstein et al. 2011, Koch and Schmidt 2010). Still others claim that disclosure laws have limited effects on prescribing behavior (Pham-Kanter et al. 2012, Guo et al. 2017) and, as such, merely increase the cost of doing healthcare. Despite such speculative arguments, however, the interaction of disclosure laws with the mediating channel of industry-physician relationships remain unknown.

It is difficult to analyze the interaction of disclosure law with payments, and no previous study has examined whether payments to physicians from pharmaceutical companies are lower when disclosure is mandatory. Data for this type of comparative empirical analysis are rarely available, have previously been of poor quality (Ross et al. 2007), and data are typically only available for states that have instituted disclosure requirements. Researchers have had to rely on physician self-reporting of payments in non-disclosure states. We bypass this obstacle by utilizing national data released by pharmaceutical companies due to legal settlements unlikely to have been predicted at the time physicians received payments.

The scope and size of our data also make it a more comprehensive industry-wide analysis. Twelve U.S. pharmaceutical companies representing $42 \%$ of total pharmaceutical industry rev- 
enues released data on payments from 2009-2011 totaling to $\$ 316$ million to 316,622 physicians in 50 states and Washington, D.C. States were classified as having disclosure laws that were strong (3 states-Massachusetts, Vermont, and Minnesota), weak (4 states-West Virginia, District of Columbia, Maine, and California), or non-existent (44 states) based on whether data were reported to state authorities (weak) or was made publicly available (strong). Our analysis of state laws is limited by the lack of true randomization of laws or randomization of the assignment of decision-makers responsible for creating the law. There is no way to rule out omitted variables without a randomized control trial of laws, so our study faces the same limitation as other studies of the impact of policies without random assignment. Thus, we use two approaches in our analysis of disclosure laws and payments to physicians. First, we use a multiple regression in a cross-sectional framework and assess whether our estimates change significantly with the inclusion of controls that may be correlated with both the laws and the payments. Our second approach employs a differences-in-differences panel framework to control for unobserved differences that are fixed within states. In both analyses, we find that state-mandated public disclosure of pharmaceutical payments to physicians was associated with lower statewide average payment per physician, but higher payments among the subset of physicians with industry relationships. The quantitative estimates across all payments and for each payment category were similar, which reduces the concern that our results are due to omitted variables, though we cannot completely rule out that possibility.

For one state - Massachusetts - existing state-mandated disclosures first became publicly available during our sample period, allowing separate analyses of the association between disclosure laws and public visibility of disclosed data while the administrative cost of reporting data remained fixed for pharmaceutical companies. We use the date the data became publicly visible as the treatment date for two reasons. First, this allows disentangling the behavioral response by physicians to mandatory disclosure from the behavioral response by industry to the costs of complying with mandatory disclosure. Second, we lack data covering the period before the date the state-mandated disclosure data began to be collected. The results corroborate the cross-sectional finding. While the number of payments to physicians decreases, the average amount of payments increases among physicians who accepted payments. This suggests that the public visibility of the disclosed data, rather than the disclosure itself, is the primary mechanism behind our findings. 
This is further corroborated by the fact that in our analysis states with weak disclosure laws are indistinguishable from states with no disclosure laws.

On a theoretical level, our paper contributes to a literature on expert advisors. Many papers have modeled the reputational concerns of expert advisors (Sobel 1985, Benabou and Laroque 1992, Morris 2001), but only two previous models, as far as we are aware, examine the effects of mandatory disclosure (Li and Madarász 2008; Inderst and Ottaviani 2012). Li and Madarász (2008) examines the effect of mandatory disclosure on the advice of experts, whereas we model the effect of mandatory disclosure on the disclosed activity. Our model makes a technical contribution by bounding the reduction in information rent accruing to remaining agents when less efficient agents are shut down in an adverse selection model where outside opportunities increase. We show that raising the opportunity cost of agents in an adverse selection model unambiguously

raises the payment to all types who still receive payments. Inderst and Ottaviani (2012) present a different model where firms' commissions (payments) to intermediaries steer the advice of intermediaries and attract customers, but mandatory disclosure stifles all payments because it reduces customers' willingness to pay. However, Inderst and Ottaviani (2012) does not predict mandatory disclosure to increase payments among those already receiving large payments. Our paper also contributes to a large, primarily informal, mandatory disclosure literature in law (BenShahar and Schneider 2014), accounting (Leuz and Verrecchia 2000), and lobbying. A related paper models the effects of third-party funding on the reputation of experts and, like this paper, tests the model using confidential data (Chen 2015).

The rest of the paper proceeds as follows. Section 2 presents the theory which provides intuition for the potential effects of mandatory disclosure on the disclosed activity. Section 3 describes the data. Section 4 explains the empirical strategy and threats to the validity of the identification strategy. Section 5 presents the results. Section 6 discusses the findings and concludes.

\section{THEORY}

This section seeks to understand why disclosure laws may have behavioral effects. The following is a simple theory for the potential impact of disclosure law on physician payments. First, the payoff to paid physicians is predicted to increase after mandatory disclosure because of the 
reputational cost to physicians of having their industry-physician relationships be made public. Second, physicians receiving low payments drop out with mandatory disclosure because it is not worth it to the pharmaceutical companies to continue paying these physicians. We illustrate the intuition in a two-type model and a full model with continuous types in the online appendix.

In brief, suppose each physician can be categorized according to a certain number of ways in which they may increase pharmaceutical sales. For example, some physicians may be more successful at conducting clinical research that advance marketing claims or find additional indications for a particular drug. Other physicians may be more effective at presenting the results of clinical research to colleagues and affecting peer prescribing behaviors. Some physicians may simply be more behaviorally responsive to payments in their prescribing patterns. The pharmaceutical company's objective, for a given physician type, is to maximize the payoff of payments. The payoff for effective physicians will be higher than the payoff for less effective physicians.

Now, consider the effect of disclosure. We assume that disclosure law increases the cost of each physician for the pharmaceutical company. Disclosure effectively makes physicians more reluctant to accept payments. The reputational cost of accepting payments is passed onto the pharmaceutical company, which then must make higher individual payments to achieve the same effect with a particular physician. Then, mandatory disclosure has two effects. First, mandatory disclosure increases the payoffs to the paid physicians, because for a given physician effort, the payment to the physician increases. Second, mandatory disclosure increases the cutoff threshold for physician effectiveness. The pharmaceutical company will choose not to pay physicians who are less effective than this cutoff. So, mandatory disclosure causes low payments to drop out.

\section{DATA}

We identified payments to physicians between 2009-2011 using public disclosures from 12 pharmaceutical companies. The combined revenue of the companies represented $42 \%$ of U.S. market revenue in 2011. ${ }^{1}$ Two companies made payment data available voluntarily, and data from the remaining 10 companies became available due to legal action - typically as a result of legal settlements with the U.S. Department of Justice. ${ }^{2}$ These data were collated and provided by a

\footnotetext{
${ }^{1}$ Appendix 1, which reports background information on these companies, displays this information in Panel A.
}

${ }^{2}$ Appendix 1 Panel B summarizes the conditions for each pharmaceutical company disclosing the payments. 
non-profit journalism organization, ProPublica. We conducted several validation checks of the data. First, we validated this database with data obtained directly from seven pharmaceutical companies. ProPublica assembled data on payments to physicians from 12 pharmaceutical companies, between the third quarter of 2009 and fourth quarter of 2011. This compilation was important because historical data are not easily obtainable from all pharmaceutical companies directly. For example, some companies remove data from their website at the end of each quarter or year. We partially validate the quality of the ProPublica data, by comparing it with data obtained directly from Eli Lilly, for payments made to physicians during 2010. We found a match of greater than or equal $97.5 \%$ for the number of physicians and total amount of payments, in each category and overall. Similarly high match rates were found for Astrazeneca payments made in 2010, GlaxoSmithKline payments made in 2009 Quarters 2 to 4, Johnson \& Johnson payments made in 2010, Merck payments made from 2009 Quarter 3 to 2010 Quarter 4, Valeant payments made in 2010 Quarters 1 to 3, and Viiv payments made in 2010. ${ }^{3}$ Other data were not reported in a quarterly or yearly time frame available for comparison. When we excluded voluntarily disclosed data in robustness checks of our specifications, the results were similar.

Our data contained 579,652 payments made from the third quarter of 2009 to second quarter of 2011. We also excluded 707 payments for which an individual recipient could not be identified. 316,622 physicians and $\$ 316$ million in payments were represented in our data. Each payment included the name of the pharmaceutical company providing payment, name and city of the physician receiving payment, date, amount, and category of payment (consulting, speaking, research, meals, travel/lodging, items, other, or combination of above categories). We cannot verify whether pharmaceutical companies assigned the most relevant payment category to transactions, as contract terms are typically private and may include provision of promotional or marketing support (Steinbrook 2009).

If a payment range was specified (e.g., " $\$ 10,001-\$ 20,000 ")$, the average reported payment within that range was used. Most companies reported data at the annual level, so we generated equivalent data for the remaining companies by summing the payments by year. Physician identifiers were created based on the same name (first, last, and middle) and city appearing in multiple disclosure records. For a match across payment records, we required the same first and last name, and either

\footnotetext{
${ }^{3}$ Appendix 1 Panel $\mathrm{C}$ presents a full discussion of the validity of our data.
} 
the same middle name (or initial) or city; no other data were available for the match.

Various governmental and non-profit organizations provided data on statewide health and socioeconomic conditions. ${ }^{4}$

We classified state disclosure laws as "strong" if states required payments to physicians to be publicly available, "weak" if states required payments to physicians to be reported to the state but not the general public, and "none" if states did not require reporting of payments to physicians. Table 1 summarizes the dates of passage of laws and categorizes the strength of disclosure laws by state. In Massachusetts, payments from drug companies and medical device makers to healthcare providers were required to be disclosed to the general public. In Minnesota, payments of over $\$ 100$ from wholesale drug manufacturers to practitioners were required to be generally disclosed to the public. In Vermont, payments from prescription drug companies to healthcare providers were required to be disclosed to the general public. In Massachusetts, the data became publicly searchable on a website in November 2010. For Minnesota and Vermont, the data can be requested from the state attorney general offices. In West Virginia, payments above $\$ 100$ from drug companies to healthcare providers, for the purpose of advertising prescription drugs were disclosed to the state. In Maine and the District of Columbia, payments for seminars, informational programs, trips and travel, food, entertainment, or gifts valued at more than $\$ 25$ and anything provided to a healthcare professional for less than market value were required to be disclosed to the state. In California, pharmaceutical companies are required to self-impose an annual limit on marketing expenses to healthcare professionals. In West Virginia, District of Columbia, Maine, and California, any payment data disclosed to the state was kept confidential.

\subsection{Outcomes}

The main dependent variable was the $\log$ of average payments per year ${ }^{5}$, calculated as the total annual amount paid to all physicians in a state each year ("statewide payments") divided by the number of physicians with active licenses in each state ("number of active physicians"). In additional tests, we examined the share of statewide payments in each category and number of physicians accepting any payment. We also analyzed annual payments to individual physi-

${ }^{4}$ These variables are listed along with their sources in Appendix 2.

${ }^{5}$ We used logs because distribution of payments was more reflective of log-normal rather than normal distribution. 
cians among the subset of physicians who accepted at least one payment ("paid physicians") as well as the distribution of payments above and below $\$ 1,000$ and $\$ 100$ - the limit on industry gifts to physicians suggested by both the AMA (1992) and Pharmaceutical Researchers and Manufacturers of America (2009).

\subsection{Potential Confounders}

We control for potential confounders that may influence the interest of pharmaceutical companies in associating with physicians in these states. Physicians earning a lower income or residing in states with a higher cost of living may have greater interest to supplement income through payments from pharmaceutical companies. Special considerations may be taken into account when prescribing medications for children (differential safety, dosage, duration, etc.); a large elderly population is likely to reflect a bigger market share for prescription drugs, increasing the interest of pharmaceutical companies to associate with physicians in these states. Individuals with health insurance, higher wealth, or education may be more able to afford prescription medications. Bigger prescription drug market size, dense populations, and more physicians with active licenses may make pharmaceutical associations more effective, for example, through more interaction with other physicians on a regular basis, whether casual or through well-attended speaking engagements. Nurses with active licenses may be an alternative target of association for pharmaceutical companies. We obtain cost of living, average physician wages, median household income, and the proportion of individuals with health insurance from the US Departments of Labor and Commerce. We measure population density and the proportion of individuals under 18 years of age, greater than or equal to 65 years, and with at least a high school education from

the U.S. Census Bureau. The Kaiser Family Foundation provided data on the average number of retail prescriptions per person that were filled at pharmacies in 2011. The AMA and American Hospital Association provided data on the number of physicians and nurses in each state with active licenses, respectively.

In robustness checks, we used sparse models to assist in the selection of controls (Belloni et al., 2014, Belloni et al. 2012). Controlling for a large set of variables is desirable from the standpoint of mitigating potential biases underlying the interpretation of the disclosure law coefficient. The 
downside is that controlling for too many variables may make estimates become less precise. The researchers are faced with a trade-off between the precision of the estimate and the plausibility of the conditional exogeneity assumption. By including additional controls in the specification, we make the conditional exogeneity assumption more plausible. At the same time, the precision of estimates is potentially reduced. The double selection method by LASSO offers a rigorous approach to achieving a balance between exogeneity and precision (Belloni et al., 2014, Belloni et al. 2012). ${ }^{6}$

Formally, LASSO modifies ordinary least squares by minimizing the sum of squared errors subject to the sum of the absolute value of all coefficients being less than a constant. This constraint tends to set some coefficients to exactly 0 , reducing model complexity by identifying only the most important variables. Estimation proceeded in two steps. First, LASSO selected the control variables that predict the strength of the disclosure law. This step helps to ensure robustness by finding control variables that are strongly related to the treatment and thus potentially important confounds. Next, LASSO selected control variables that were predictive of payments. This step helps to ensure that important elements are included in the equation, helping keep the residual variance small as well as intuitively providing an additional chance to find important confounds. LASSO used a set of potential confounding factors constructed from the original controls and, as

${ }^{6}$ Determining which variables to select as controls is a frequent problem in observational studies. Typically, intuition suggests a set of variables that might be important but does not identify exactly which variables are important or the variables' functional forms and interactions. This lack of clear guidance about which variables to use leaves researchers with the problem of attempting to select a sensible set of controls from a potentially vast set of variables. As such, LASSO may be a useful tool to strengthen observational studies in the clinical literature. The basic problem in estimating the relationship between disclosure law and pharmaceutical company payments to physicians is that disclosure law is likely endogenous to important economic or social factors. These factors may be associated with both the strength of the disclosure law and pharmaceutical company payments. If these factors are important, they could drive a spurious association between disclosure law and pharmaceutical company payments. We assess the stability of coefficients to including obvious confounding factors, such as the existence of persistent state-to-state differences in policies, demographics, and culture that are probably related to disclosure laws and the overall level of pharmaceutical company payments to physicians (either by modifying the desirability of physicians to pharmaceutical company marketers or the willingness of physicians to accept payments from pharmaceutical companies). It is also important to control flexibly for state-to-state differences. Interpreting correlations from our basic specification as unbiased relies on the belief that there are no higherorder terms of the control variables, no interaction terms, and no additional excluded variables that are associated both to disclosure laws and pharmaceutical company payments to physicians. Interpretation also relies on the belief that payments do not lead to different types of disclosure laws. While this must be ruled out on a priori grounds, justifying the belief of no omitted variables requires more work. LASSO complements the usual careful specification analysis by providing a researcher a simple-to-implement, data-driven way to search for a set of influential confounds from among a sensibly chosen broader set of potential confounding variables. Empirical studies usually rely on a sensitivity analysis to report results for several different sets of controls, to show that the parameter of interest is robust to changes in the set of control variables. The tables in Appendices 3 and 7 reports the results using LASSO to select potential confounders, and the result of this selection is reported in Appendix 8. 
standard practice, all two-way interactions between any two controls. ${ }^{7}$ The original controls plus LASSO-selected control variables were then included as independent variables. ${ }^{8}$ LASSO is not a perfect solution to omitted-variables bias: the cross-sectional regressions can still be misleading to the extent that important confounding factors are left out of the feature set, hence the need for a difference-in-difference approach to complement the cross-sectional approach.

\section{ESTIMATION FRAMEWORK}

\subsection{Cross-sectional specification}

Our multiple regression model used the following framework:

$$
\log \left(Y_{s t}\right)=\beta_{0}+\beta_{1} L a w_{s t}+\beta_{2} \text { Year }_{t}+\beta_{3} X_{s t}+\epsilon_{s t}
$$

where $Y_{s t}$ is the ratio of sum of all payments received, over the number of active physicians in state $s$, year $t .{ }^{9} L_{\text {Lw }}$ are dummy variables indicating strength of disclosure laws in state

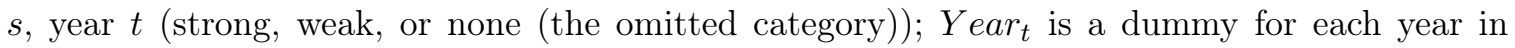
our sample; and $X_{s t}$ are state and year controls, including the share of payments from each company, the share of payments for each category of payment, and health and socioeconomic controls as described above. We use heteroscedasticity-robust Huber-White standard errors or standard errors clustered at the state level.

For alternative specifications, we also looked at:

$$
\log \left(Y_{i s t}\right)=\beta_{0}+\beta_{1} L_{a w}+\beta_{2} \text { Year }_{t}+\beta_{3} X_{s t}+\epsilon_{i s t}
$$

${ }^{7}$ Additional description of and motivation for the LASSO variables are in Cohen and Chen (2010).

${ }^{8}$ We also included Share of Payments from Each Pharmaceutical Company by Value and by Count and Share of Payments in each Payment Category by Value and by Count. However, all results at the state and physician level and at various thresholds were robust to dropping control variables for share of payments from each company and share of payments for each category of payment. In fact, the relationships became larger and more statistically significant.

${ }^{9}$ We specified payments in logs because we rejected the hypothesis that payments in non-log terms were normally distributed using the one-sample Kolmogorov-Smirnov test against the theoretical distribution. 
where $Y_{i s t}$ is now sum of all payments received by physician $i$ in state $s$, year $t$, and the right-hand side variables having the same notation as the aggregate version. When we analyze payments above or below cutoffs like $\$ 1,000$ and $\$ 100$, we check robustness of the results to implementing truncated regressions. ${ }^{10}$

Finally, for the third specification, we looked at:

$$
\log \left(Y_{c s t}\right)=\beta_{0}+\beta_{1} L_{a w}+\beta_{2} Y_{e a r_{t}}+\beta_{3} X_{s t}+\epsilon_{c s t},
$$

where now $Y_{c s t}$ is the sum of category $c$ payments received, divided by the sum of all payments in state $s$, and year $t$.

\subsection{Differences-in-differences specification}

For the differences-in-differences specification, we used the following framework:

$$
\log \left(Y_{\text {st }}\right)=\beta_{0}+\beta_{1} \mathbb{1}_{M}+\beta_{2} \mathbb{1}_{M} \text { Post }_{t}+\beta_{3} \text { Year }_{t}+\beta_{4} X_{s t}+\epsilon_{s t}
$$

where $Y_{s t}$ is the sum of all payments, over the number of active physicians in state $s$, year $t$; $\mathbb{1}_{M}$ is an indicator variable for the state of Massachusetts; Year $t_{t}$ and $X_{s t}$ are as defined before; the year fixed effects absorb the post dummy. Standard errors are clustered at the state level.

As an alternative specification, we also consider:

$$
\log \left(Y_{\text {ist }}\right)=\beta_{0}+\beta_{1} \mathbb{1}_{M}+\beta_{2} \mathbb{1}_{M} \text { Post }_{t}+\beta_{3} \text { Year }_{t}+\beta_{4} X_{\text {st }}+\epsilon_{\text {ist }},
$$

where $Y_{i s t}$ is now sum of all payments received by physician $i$ in state $s$, year $t$, and the right-hand side variables having the same notation as the aggregate version.

\footnotetext{
${ }^{10}$ To reduce the impact of outliers, we also replaced the top $0.5 \%$ of payments with the 99.5 th percentile. We varied this parameter between the top $0.5 \%$ and $2.5 \%$, with similar results. Results were robust to eliminating payments reported in ranges.
} 
To assess the validity of our estimates, we used randomization inference: we re-ran these regressions, re-assigning the indicator variable to another state. We report whether the true $\beta_{2}$ falls outside the 90 or $95 \%$ range of placebo $\beta_{2}$ estimates. There is no pre-trend data to assess parallel pre-trends before the data were revealed online because most of the data is yearly. In the appendix, we employ synthetic control and report point estimates similar to the main estimates.

\section{RESULTS}

\subsection{Cross-sectional association between disclosure laws and payments (state-level analysis)}

We preview our results with mean statistics and distributional visualizations before moving to the regression analyses. First, we looked at differences in payments between states with strong, weak, and no disclosure laws. We compared the magnitude and category of payments according to disclosure status. Table 2 presents summary statistics. In the bottom the first panel, 11\% of physicians in strong-disclosure states accepted payments, versus $37 \%$ and $42 \%$ of physicians in states with weak and no disclosure laws, respectively. Among the 316,622 physicians ${ }^{11}$ who accepted payments across the U.S., the average annual payment was $\$ 1,377$ (standard deviation $=\$ 6,694) .{ }^{12}$ The second panel displays the average payments per physician in the different states. It shows that statewide payments per physicians is $\$ 221$ in strong-disclosure states and $\$ 334$ in weak-disclosure states and $\$ 411$ in non-disclosure states. Speaking fees comprise the largest share across all categories and states. It also shows that strong-disclosure states have lower average payments for speaking and for meals and higher payments for consulting. The third panel displays the average payments per paid physician in the different states. It shows that physicians in strong-disclosure states had proportionately larger payments for consulting. The absolute payment amount for research activities is larger in strong-disclosure states. The fourth panel displays the proportional distribution of payments across payment types for different categories of disclosure law strength. It shows similar patterns are also present in terms of proportions.

Figure 1 displays the cumulative density of payments by strength of disclosure law. It displays

\footnotetext{
${ }^{11} 316,622=6,689+38,209+271,724$ from the third row of this panel.

${ }^{12}$ This is the weighted average of the final row of the third panel.
} 
annual payments among paid physicians (observations are at the physician-year level). The cumulative density line for states with no disclosure law and for states with weak disclosure law indicates that in both groups of states, $90 \%$ of the annual payments among paid physicians are below $\$ 1000$. This can be seen by drawing a vertical line at $\$ 1000$ on the $\mathrm{x}$-axis. When Massachusetts, Minnesota, and Vermont are averaged, $81 \%$ of the physicians in these states were paid less than $\$ 1000$ annually. Massachusetts - the state with the most recent implementation of a strong disclosure law - exhibited the lowest proportion of paid physicians receiving payments greater than $\$ 1,000$ among strong-disclosure states and diverged least from weak and non-disclosure states in this regard. States under strong disclosure laws for longer periods of time had higher proportions of highly paid physicians. The distributions were significantly different at $\mathrm{P}=0.001$.

Figure 1 also presents the analyses of Massachusetts, Minnesota, and Vermont separately in order to examine the $\$ 100$ cut-off. The disclosure obligations in one strong disclosure state (Minnesota) and one weak disclosure state (West Virginia) required payments of over $\$ 100$ to be reported to the public or state attorney general offices. However, litigation settlements obliged all payments to be reported. To the extent the administrative burdens surrounding payments in excess of $\$ 100$ and lack of administrative burdens for payments under $\$ 100$ meant that payments under $\$ 100$ should be more common (than in states without disclosure obligations), this is not apparent in the data. Up to $60 \%$ of annual physician payments are less than $\$ 100$ in Minnesota, which is in between the percentage share for the other two strong disclosure states (Massachusetts and Vermont), which is suggestive evidence that administrative burden of reporting was not a significant determinant of the payments. However, the derivative in the cumulative distribution is highest for Minnesota at $\$ 100$, while the distribution of payments for West Virginia is very similar to the distribution of payments for no disclosure states. This difference-in-discontinuity supports the view that disclosure affects the reputational costs to physicians, who would discontinuously experience this cost at $\$ 100$ and only in strong disclosure states.

We used multiple regression models to relate physician payments to the presence of strong, weak, or no disclosure laws, controlling for the pharmaceutical company providing payment, category of payment, year, and controls described above. The unit of analysis is the state-year with 153 observations across 3 years. Adjusted for all controls, statewide payments per physician 
were $49 \%$ lower in strong-disclosure states $(95 \% \mathrm{CI}=-0.716,-0.259, \mathrm{P}<0.001$, Table 3$)$ than in non-disclosure states. Statewide payments were not significantly lower in weak-disclosure states (coefficient $=-0.176,95 \% \mathrm{CI}=-0.394,0.041, \mathrm{P}=0.11$ ) (Table 3) than in non-disclosure states. Both of these results are consistent with regression models that include different sets of potential confounds. ${ }^{13}$

Using multiple regression models, we also estimated the relationship between disclosure laws and the share of payments in each category, and the relationship between disclosure laws and the number of physicians receiving payments. Compared to total payments per category in nondisclosure states, adjusted for all controls, the share of total payments per category in strongdisclosure states was as follows: $10.5 \%$ lower share for speaking $(\mathrm{P}=0.005), 3.1 \%$ lower share for meals $(\mathrm{P}=0.05)$, and $9.4 \%$ higher share for consulting $(\mathrm{P}<0.001)^{14}$. Weak-disclosure states had, in contrast, a $2.8 \%$ higher share of payments for meals and $2.1 \%$ lower share of payments for consulting than in non-disclosure states (both $\mathrm{P}=0.05$ ). A chi-squared test of differences between payment categories by strength of disclosure laws was significant $(\mathrm{P}<0.001)$.

\subsection{Cross-sectional association between disclosure laws and payments (physician-level analysis)}

Next, we analyzed the association between disclosure laws and payments received by physicians at the individual (rather than state) level. The unit of analysis is physician-year. Table 3, column 2 considers the subset of physicians who accepted any payment from pharmaceutical companies. In strong-disclosure states, annual payments among physicians who accepted any payment were $10.1 \%$ higher $(95 \% \mathrm{CI}=0.0096-0.193, \mathrm{P}=0.03)$ than in non-disclosure states. This result is robust to various sets of controls. ${ }^{15}$ Average annual payments among physicians who accepted any payments was $\$ 2,436$ in strong-disclosure states and $\$ 1,340$ in non-disclosure state (and $\$ 1,467$ in weak-disclosure states). In weak-disclosure states, annual payments were $8.8 \%$ lower $(\mathrm{P}<0.001)$ than in non-disclosure states, but the sign of this association was reversed in specifications with fewer controls.

We evaluated different thresholds for payments to ascertain the parts of the payment distribu-

${ }^{13}$ Appendix 3 displays a sequence of models where control variables are gradually added to assess sensitivity of the main results.

${ }^{14}$ Appendix 4 reports the complete set of regression coefficients.

${ }^{15}$ Appendix 3 sequentially adds controls in models 7-9. 
tion that were associated with disclosure laws. Doing so assesses a prediction of the model. The model says that (1) low-money physicians simply drop out and (2) high-money physicians get more money. We used a multiple regression analysis similar to the aggregate approach. The unit of analysis is physician-year. Some specifications include only physician-years when a physician received any payments. Other specifications include all active physician-years, assigning $\$ 0$ to physicians not receiving payments.

In strong-disclosure states, annual payments among physicians who accepted greater than $\$ 100 /$ year were $54 \%$ higher $(95 \% \mathrm{CI}=0.411-0.675, \mathrm{P}<0.001)$ (Table 3 , column 3$)$ than in nondisclosure states. No statistically significant association was observed between strong disclosure laws and the number of physicians who accepted greater than $\$ 100 /$ year. However, in strongdisclosure states, roughly $19 \%$ of paid physicians accepted payments greater than $\$ 1,000$, compared with only $10 \%$ of physicians in weak-disclosure states and non-disclosure states. States with less time spent under strong disclosure laws had a smaller percentage of paid physicians accepting payments greater than $\$ 1,000$.

No statistically significant association was observed for strong disclosure laws and size of payments among paid physicians who accepted less than or equal to $\$ 100 /$ year, but the number of such physicians was $68 \%$ lower $(95 \% \mathrm{CI}=0.058-1.294, \mathrm{P}=0.032)^{16}$ than in non-disclosure states. When including all physicians (not just those who received payments), annual payments among physicians who accepted less than or equal to $\$ 100$ /year were $25 \%$ lower $(95 \% \mathrm{CI}=0.249-0.260$, $\mathrm{P}<0.001$ ) (Table 3, column 4). Payments among physicians who accepted less than or equal to $\$ 100 /$ year were significantly different in states with weak versus no disclosure laws, but the significance disappears in the truncated regression with clustering at the state level. ${ }^{17}$

\subsection{Differences-in-differences association between disclosure laws and payments (physician-level} analysis)

One state in our sample, Massachusetts, enacted a strong disclosure law in January 2009, but first publicly released data in November 2010 (Kowalczyk 2010). To examine the impact of this

\footnotetext{
${ }^{16}$ Appendix 5, which reports additional analyses of the relationship between disclosure laws and distribution of payments to physicians, shows this result in column 2 .

${ }^{17}$ Appendix 7, which reports additional analyses of the relationship between disclosure laws and payments to physicians, shows this result in column 4.
} 
release, we ran a differences-in-differences analysis that compared the change in payments in Massachusetts pre- versus post-November 2010 with the change in payments in all other states (none of which altered transparency during this time period). Units of analysis are state-year and physician-year.

Following public release of disclosed payments, payments per physician in Massachusetts decreased 36\% ( $\mathrm{P}<0.001)$ (Table 3, column 5) relative to all other states (which did not change publication of disclosures during this time period). The share of Massachusetts payments declined by $7 \%$ for speaking and $4 \%$ for meals, but rose $9 \%$ for research and $1 \%$ for consulting (the first three $\mathrm{P}<0.001$ and the last $\mathrm{P}<0.1) .{ }^{18}$ However, because of the large decrease in payments per physician overall, the absolute amount within each of the categories was reduced. When we used randomization inference, re-assigning the indicator variable to each of the other states, the estimated decrease for overall payments, meals, travel, was between the 90th and 95th percentile of the alternative estimates.

Although not statistically significant, the number of Massachusetts physicians receiving any payment and payments less than $\$ 100$ declined $34 \%(\mathrm{P}=0.112)$ and $13 \%(\mathrm{P}=0.125)$, respectively. Payments among Massachusetts physicians who accepted greater than $\$ 100 /$ year increased $69 \%$ $(\mathrm{P}<0.001)$ while payments among those who accepted less than $\$ 100 /$ year decreased by $6.9 \%$ $(\mathrm{P}<0.001)$ (Table 3, columns 6-7) relative to all other states. When we re-assigned the indicator variable to each of the other states, the estimated decrease in payments among those who accepted less than $\$ 100 /$ year was between the 90th and 95th percentile of the alternative estimates.

\section{DISCUSSION AND CONCLUSION}

Many hope that disclosure policies will result in more evidence-based prescribing decisions, better patient outcomes, and decreases in total expenditures on prescription drugs - the fastest growing component of healthcare costs. However, the interaction of disclosure laws on the mediating channel of industry-physician relationships remains unknown. This paper presents a model of the potential impact of disclosure law on the disclosed activity. These effects have not been previously modeled as far as we are aware nor have they been empirically examined. The interaction

\footnotetext{
${ }^{18}$ The regression analyses of Massachusetts' disclosure is shown in Appendix 6 .
} 
of disclosure laws on the targeted behavior is typically unknowable since data on disclosed activity rarely exist in the absence of disclosure. We bypass this obstacle by utilizing national data released by pharmaceutical companies due to legal settlements unlikely to have been predicted at the time physicians received payments.

Strong disclosure laws were associated with a $49 \%$ lower statewide annual average of payments to physicians and $74 \%$ lower proportion of physicians receiving payments. These decreases might be considered an intended result of disclosure legislation. However, among physicians who accepted any payment, annual payments were $10 \%$ higher in strong-disclosure states, and payments were $54 \%$ higher among physicians who accepted more than $\$ 100 /$ yr.

Physicians in strong-disclosure states had proportionately smaller payments for speaking and for meals and larger payments for consulting. The absolute payment amount for research activities is larger in strong-disclosure states. These observations suggest that rather than stigmatizing industry-physician research relationships, public disclosure of payments may instead encourage explicit and formal delineation of industry-physician relationships around consulting, research and development activities.

Little association was observed between payments to physicians and disclosure laws that did not mandate disclosure of payments to the public. This finding may explain the limited effects of disclosure laws in West Virginia and Maine on prescribing behavior in two drug classes observed in a recent study (Pham-Kanter et al. 2012). The disclosure requirements in the Affordable Care Act, however, are more similar to the strong disclosure laws in our study.

Our results shed light on whether the interaction of disclosure law with the targeted behavior is mediated through administrative costs imposed on industry or through physicians' willingness to accept payments (our model highlights the reputational cost to physicians of having their industry-physician relationships made public). Two considerations suggest that administrative costs imposed on industry are the lesser of the two mechanisms in our results. First, strong and weak disclosure imposes similar administrative costs. Second, the changes observed in Massachusetts after public release of disclosures were similar to the smaller payments noted for strong disclosure states. In addition, the categories of payments shifted in the same way-more in consulting and research and less in speaking and meals in strong disclosure states-using both cross-sectional and longitudinal variation. These results suggest that the reduction of incidental 
payments was due to decreased willingness among physicians to accept payments and that the cost of compliance with disclosure requirements did not significantly reduce industry willingness to maintain payment relationships with physicians. Moreover, to the extent that weak disclosure laws can theoretically have other behavioral effects, such as expressive or moral effects that can be reflected in payments, we do not observe them in the data.

Third, higher payments for paid physicians were observed when physician payments were publicly visible. This result is consistent with physician-level factors such as compensation demanded for increased public visibility and associated reputational costs (Sigworth et al. 2001) or a "compensation race" driven by physicians demanding more for their contracts, the availability of information on colleagues' compensation, and being under-paid (Preker 2007) or a sense of entitlement (Lichter 2008). The observed changes may be due to a compositional shift in the physicians receiving payments or a change in payments within physicians. When we include physician fixed effects, which utilizes doctors' pre-period payment receipts, strong disclosure was associated with higher payments per physician, but the association was not statistically significant at conventional levels. Therefore, some of the differences may be due to composition effects or treatment effects. It is possible that in some instances, physicians who previously received large payments now receive larger payments, and that in other instances, new physicians began receiving the larger payments.

We only had data from 12 pharmaceutical companies and to some extent, the analysis relies on the assumption that the variation in laws is uncorrelated with variation in sampling; however, the 12 companies included 7 of the 10 largest firms in the U.S. market, making their activities relevant even if not representative of smaller pharmaceutical firms. ${ }^{19}$ Lower payments per physician in strong disclosure states were observed for each of the 12 companies regardless of its size. This alleviates the concern that sampling factors are associated with the identifying variation if the same pattern holds for each company. We also compared the distribution of payments by companies in the ProPublica database and by companies not in the ProPublica database using data from Massachusetts - A Wilcoxon-Mann-Whitney test for significant differences in distributions indicates that the two distributions are not significantly different $(\mathrm{P}=0.20)$.

\footnotetext{
${ }^{19}$ Analysis of the entire pharmaceutical company industry is the subject of ERC-funded work by one of the authors using data from the ACA-mandated industry-wide disclosure.
} 
The main results were similar using both cross-sectional and longitudinal variation. We examined the experience of Massachusetts before and after the state publicly released data on pharmaceutical company payments to physicians. We employed advanced statistical techniques for strengthening cross-sectional studies by using LASSO, a sparse model, to select control variables predictive of the strength of disclosure law and control variables predictive of payments. Results were similar in both the figures displaying the raw data and multiple regressions that included controls.

Finally, although we conducted our regression analysis for differences between small and large amounts at $\$ 100$, other cutoffs besides $\$ 100$ do not change the findings as indicated by our visual representation of the cumulative distribution of payments. In strong disclosure states, there are fewer small payments even if we draw the cut-off elsewhere. We also did not observe payments under $\$ 100$ to be more common in states with administrative burdens to disclose payments in excess of $\$ 100$ compared to states without disclosure obligations. Payments under $\$ 100$ are not more common in two states with administrative burdens to disclose payments in excess of $\$ 100$, further suggestive that administrative burden of reporting was not a significant determinant of the payments. Notably, the derivative in the cumulative distribution is highest at $\$ 100$ for the strong disclosure state but not the weak disclosure state. The difference-in-discontinuity also supports the view that disclosure affects the reputational costs to physicians, who would discontinuously experience this cost at $\$ 100$ and only in strong disclosure states.

Questions for future research concern the association between pharmaceutical company payments, prescribing behavior, and patient outcomes. 


\section{REFERENCES}

American Medical Association (1992): "Gifts to Physicians from Industry and Clarification to Opinion 8.061,"

Belloni, A., D. Chen, V. Chernozhukov, and C. Hansen (2012): "Sparse Models and Methods for Optimal Instruments with an Application to Eminent Domain," Econometrica, 80, 2369-2429.

Belloni, A., V. Chernozhukov, and C. Hansen (2014): "Inference on treatment effects after selection among high-dimensional controls," The Review of Economic Studies, 81, 608-650.

Ben-Shahar, O. And C. E. Schneider (2014): More Than You Wanted to Know: The Failure of Mandated Disclosure, Princeton University Press.

Benabou, R. and G. Laroque (1992): "Using privileged information to manipulate markets: Insiders, gurus, and credibility," The Quarterly Journal of Economics, 921-958.

Brennan, T. A. And M. M. Mello (2007): "Sunshine Laws and the Pharmaceutical Industry," The Journal of the American Medical Association, 297, 1255-1257.

Cain, D. M., G. Loewenstein, And D. A. Moore (2005): Conflict of Interest: Challenges and Soutions in Business, Law, Medicine and Public Policy, Cambridge University Press, chap. Coming Clean but Playing Dirtier The Shortcomings of Disclosure as a Solution to Conflicts of Interest, 104-125.

Campbell, E. G. (2007): "Doctors and Drug Companies - Scrutinizing Influential Relationships," New England Journal of Medicine, 357, 1796-1797.

Chatterji, A. K., K. R. Fabrizio, W. Mitchell, and K. A. Schulman (2008): "Physician-industry cooperation in the medical device industry," Health affairs, 27, 1532-1543.

Chen, D. L. (2015): "Can markets stimulate rights? On the alienability of legal claims," RAND Journal of Economics, 46, 23-65.

Chimonas, S., T. A. Brennan, And D. J. Rothman (2007): "Physicians and Drug Representatives: Exploring the Dynamics of the Relationship," Journal of General Internal Medicine, 22, 184-190.

Cockburn, I. M. And R. M. Henderson (1998): "Absorptive capacity, coauthoring behavior, and the organization of research in drug discovery," The Journal of Industrial Economics, 46, 157-182.

Cohen, I. G. And D. L. Chen (2010): “Trading-Off Reproductive Technology and Adoption: Does Subsidizing IVF Decrease Adoption Rates and Should It Matter?" Minnesota Law Review, 95, 485-577.

Donohue, J. M., M. Cevasco, and M. B. Rosenthal (2007): "A Decade of Direct-to-Consumer Advertising of Prescription Drugs," New England Journal of Medicine, 357, 673-681.

Gagnon, M.-A. And J. Lexchin (2008): "The Cost of Pushing Pills: A New Estimate of Pharmaceutical Promotion Expenditures in the United States," PLoS Medicine, 5, e1.

Guo, T., S. Sriram, and P. Manchanda (2017): "Let the Sun Shine in': The Impact of Industry Payment Disclosure on Physician Prescription Behavior," .

IMS Health (2011): "Top-Line Market Data 2011: Total US Promotional Spend by Type, 2011," Internet.

Inderst, R. And M. Ottaviani (2012): "Competition through commissions and kickbacks," The American 
Economic Review, 780-809.

Katz, D., A. L. Caplan, and J. F. Merz (2003): "All Gifts Large and Small: Toward an Understanding of the Ethics of Pharmaceutical Industry Gift-Giving," The American Jornal of Bioethics, 3, 39-46.

Kerber, R. (2004): "Medical Marketing: Decvice Makers Target Consumers with Their Ads," The Boston Globe.

Koch, C. And C. Sсhmidt (2010): "Disclosing Conflicts of Interest - Do Experience and Reputation Matter?" Accounting, Organizations and Society, 35, 95 - 107.

KowalczyK, L. (2010): "Prescription for Prestige," The Boston Globe.

Leuz, C. And R. E. Verrecchia (2000): "The Economic Consequences of Increased Disclosure (Digest Summary)," Journal of accounting research, 38, 91-124.

Li, M. And K. Madarász (2008): "When mandatory disclosure hurts: Expert advice and conflicting interests," Journal of Economic Theory, 139, 47-74.

Lichter, P. R. (2008): "Debunking Myths in Physician-Industry Conflicts of Interest," American Journal of Ophthalmology, 146, 159-171.

Loewenstein, G., D. M. Cain, And S. Sah (2011): "The Limits of Transparency: Pitfalls and Potential of Disclosing Conflicts of Interest," American Economic Review, 101, 423-428.

Loewenstein, G., S. Sah, And D. M. Cain (2012): "The Unintended Consequences of Conflict of Interest Disclosure," The journal of the American Medical Association, 307, 669-670.

Merrill, J. B., C. Ornstein, T. Weber, S. Wei, and D. Nguyen (2013): "Dollars for Docs: How Industry Dollars Reach Your Doctors," ProPublica.

Morris, S. (2001): "Political correctness," Journal of political Economy, 109, 231-265.

Norris, P., A. Herxheimer, J. Lexchin, And P. Mansfield (2005): "Drug promotion," What we know, what we have yet to learn Reviews of materials in the WHO/HAI database on drug promotion.

Pham-Kanter, G., C. G. Alexander, and K. Nair (2012): "Effect of Physician Payment Disclosure Laws on Prescribing," Archives of internal medicine, 172, 819-821.

Pharmaceutical Research and Manufacturers of America (2009): "Code on Interactions with Health Care Professionals," pharma.org.

Preker, A. S. (2007): Public Ends, Private Means: Strategic Purchasing of Health Services, World Bank eLibrary, World Bank.

Ross, J. S., J. E. Lackner, P. Lurie, C. P. Gross, S. Wolfe, and H. M. Krumholz (2007): "Pharmaceutical Company Payments to PhysiciansEarly Experiences With Disclosure Laws in Vermont and Minnesota," The Journal of the American Medical Association, 297, 1216-1223.

SAde, R. M. (2011): "Full Disclosure: Where is the Evidence for Nefarious Conflicts of Interest?" The Annals of Thoracic Surgery, 92, 417-420.

Santhakumar, S. And E. Y. Adashi (2015): "The Physician Payment Sunshine Act: testing the value of transparency," Jama, 313, 23-24.

Sigworth, S. K., M. D. Nettleman, And G. M. Cohen (2001): "PHarmaceutical branding of resident physi- 
cians," The Journal of the American Medical Association, 286, 1024-1025.

Sobel, J. (1985): "A theory of credibility," The Review of Economic Studies, 52, 557-573.

Steinbrook, R. (2009): "Controlling Conflict of Interest - Proposals from the Institute of Medicine," New England Journal of Medicine, 360, 2160-2163, pMID: 19403898.

Studdert, D. M., M. M. Mello, and T. A. Brennan (2004): "Financial Conflicts of Interest in Physicians' Relationships with the Pharmaceutical Industry — Self-Regulation in the Shadow of Federal Prosecution," New England Journal of Medicine, 351, 1891-1900, pMID: 15509824.

Wazana, A. (2000): "Physicians and the pharmaceutical industry: Is a gift ever just a gift?" The Journal of the American Medical Association, 283, 373-380.

Wolfe, S. M. (1996): "Why Do American Drug Companies Spend more than 12 Billion a Year Pushing Drugs? Is it Education or Promotion?" Journal of General Internal Medicine, 11, 637-639.

Zinner, D. E., D. Bolcic-Jankovic, B. Clarridge, D. Blumenthal, and E. G. Campbell (2009): "Participation of academic scientists in relationships with industry," Health Affairs, 28, 1814-1825. 

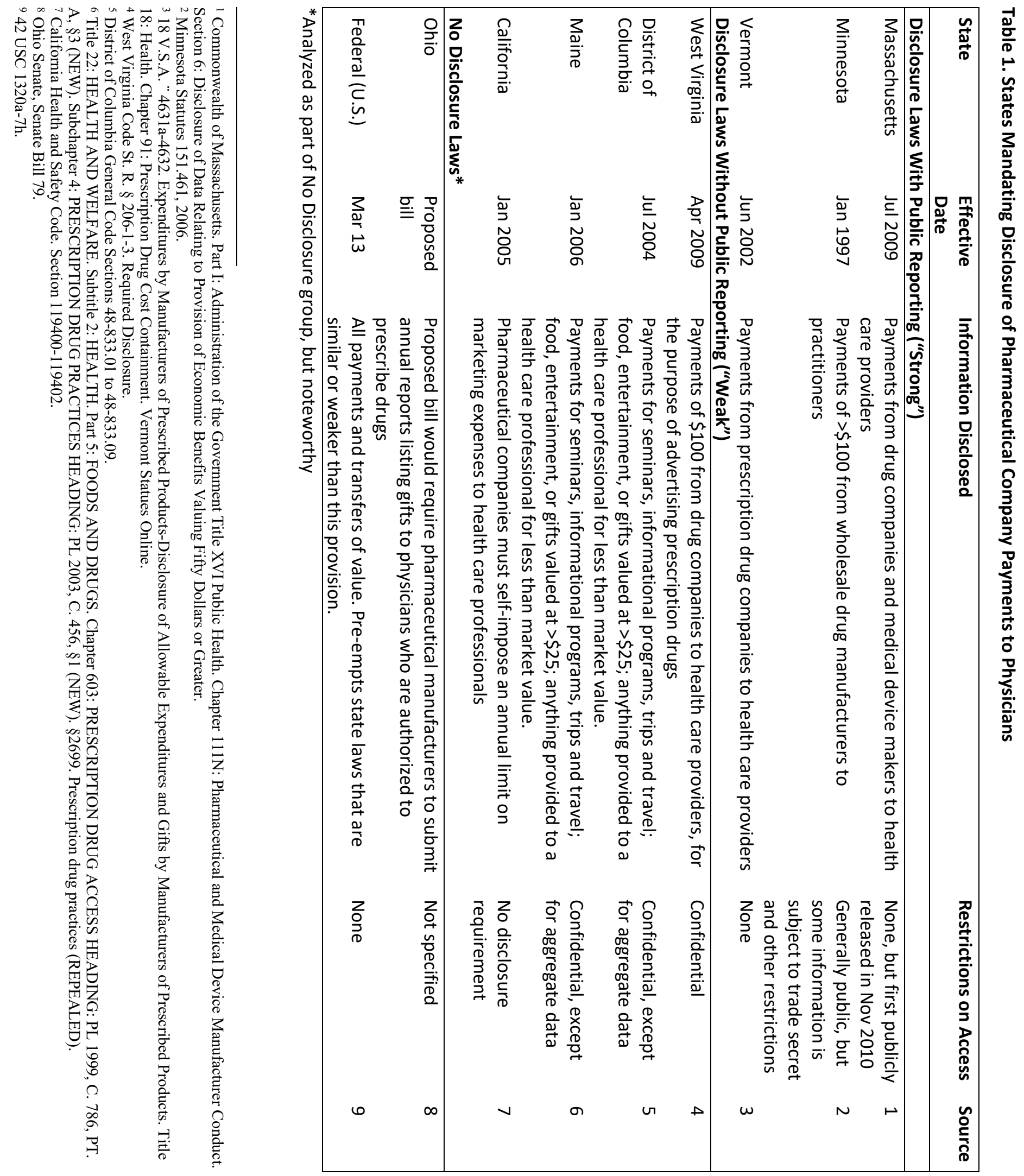
Table 2. Summary Statistics for Pharmaceutical Company Payments to Physicians, by Strength of Disclosure Laws, 2009-2011.

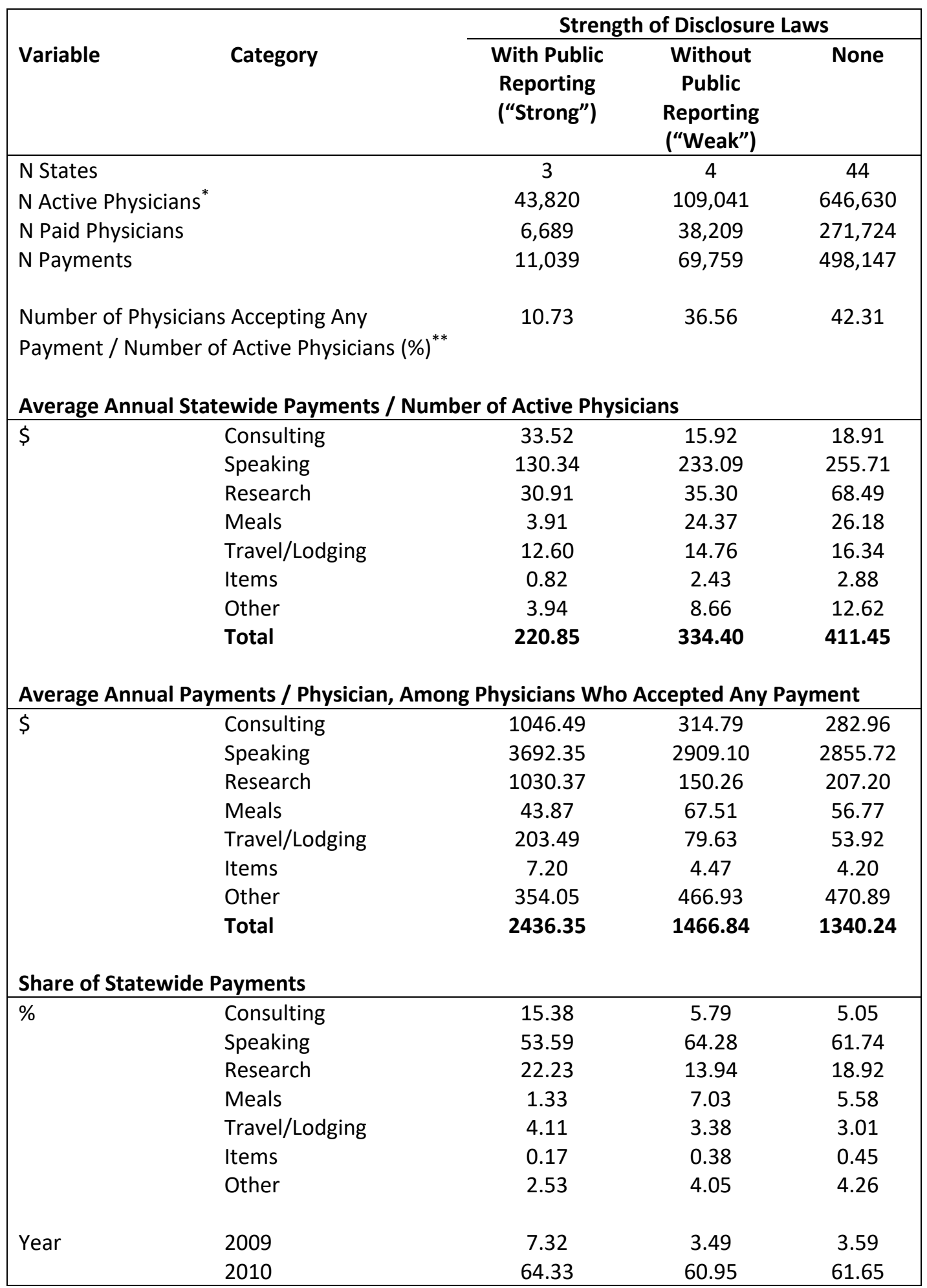




\begin{tabular}{|lccc|}
\hline \multicolumn{1}{|c}{2011} & 28.35 & 35.56 & 34.75 \\
Statewide Variables & & & \\
\hline Real Income Per Capita (\$) & & & \\
Average Physician Wage (\$) & 29,781 & 29,095 & 26,782 \\
Cost of Living & 194,797 & 190,758 & 188,748 \\
Index & 115.32 & 121.33 & 102.86 \\
Population <18 y (\%) & & & \\
Population $\geq 65$ y (\%) & 21.99 & 21.59 & 24.25 \\
$\geq$ High School Education (\%) & 13.59 & 13.58 & 13.05 \\
Health Insurance (\%) & 90.84 & 85.24 & 87.12 \\
Number of Retail Prescriptions Filled at & 76.96 & 68.28 & 71.11 \\
Pharmacies (Person/Year) & 12.23 & 13.15 & 12.14 \\
Population Density (Thousands/Square Mile) & 249.10 & 2298.41 & 162.06 \\
Number of Physicians with Active Licenses & 14,607 & 27,260 & 14,696 \\
Number of Nurses with Active Licenses & 43,933 & 67,815 & 45,775 \\
\hline
\end{tabular}

*Data for 2010.

**Average per state. 
Table 3. Relationship Between Disclosure Laws and Payments to Physicians, 2009-2011.

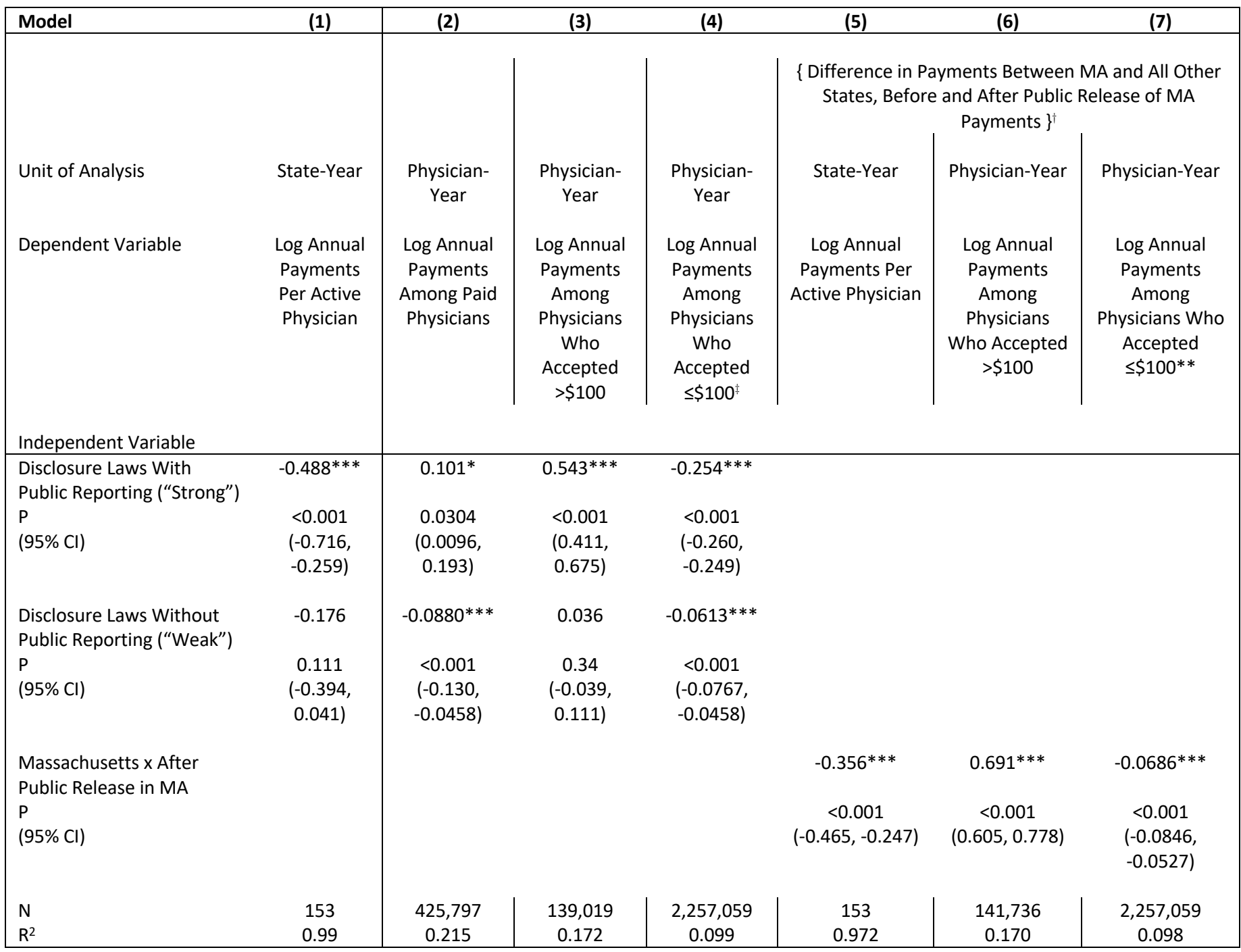

${ }^{ \pm}$Adjusted for company providing payment, category of payment, year, and statewide demographics. Demographics are household income, average physician wage, cost of living, $\%$ population $<18, \%$ population $\geq 65, \%$ unemployment, $\% \geq$ high school education, \% health insurance, annual prescription drugs filled at pharmacies/person, population density, number of active physicians, and number of active nurses. Full results displayed in Appendix 3 . Additional LASSO controls in Appendix 8. Robust standard errors.

Included a zero for physicians who accepted no payments.

†Standard errors clustered at the state-level. 
Figure 1. Cumulative Density of Payments To Physicians Who Accepted Payments (\$), 2009-2011.

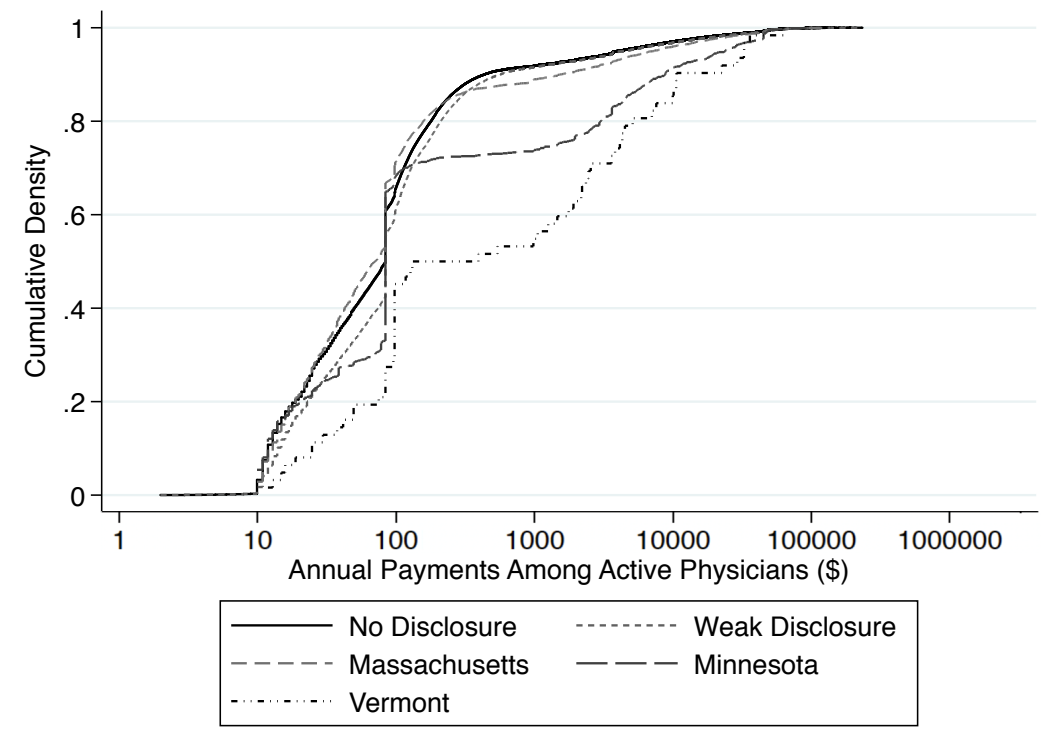




\section{REVIEWER SUPPLEMENT}

\section{Appendix 1. Disclosure of Pharmaceutical Company Payments to Physicians}

Panel A: Size of Database, May 2012

\begin{tabular}{|l|c|c|}
\hline Company & $\begin{array}{c}\text { Revenue } \\
\text { (\$ Billion, 2011) }\end{array}$ & $\begin{array}{c}\text { Market Capitalization } \\
\text { (\$ Billion, May 2, 2012) }\end{array}$ \\
\hline Allergan & 5.42 & 29.37 \\
\hline AstraZeneca & 33.59 & 56.25 \\
\hline Cephalon* & 18.31 & 43.08 \\
\hline Eli Lilly & 24.29 & 47.86 \\
\hline EMD Serono** & $\mathrm{N} / \mathrm{A}$ & $\mathrm{N} / \mathrm{A}$ \\
\hline GlaxoSmithKline & 43.93 & 117.82 \\
\hline Johnson \& Johnson & 65.03 & 179.03 \\
\hline Merck & 48.05 & 119.79 \\
\hline Novartis & 58.57 & 151.26 \\
\hline Pfizer & 67.43 & 171.7 \\
\hline Valeant & 2.46 & 16.79 \\
\hline ViiV** & $\mathrm{N} / \mathrm{A}$ & $\mathrm{N} / \mathrm{A}$ \\
\hline Total of Companies in Data & $\mathbf{3 6 7 . 0 8}$ & $\mathbf{9 3 2 . 9 5}$ \\
\hline Size of Pharmaceutical Market & 869.85 & $2,090.00$ \\
\hline Market Share & $\mathbf{4 2 . 2 \%}$ & $\mathbf{4 4 . 6 \%}$ \\
\hline
\end{tabular}

*Data shown for Teva, which acquired Cephalon in 2011.

*Private company; data not available.

** Owned by GlaxoSmithKline and Pfizer.

Sources:

Global Industry Classification Standard. Health Care-Pharmaceuticals-Pharmaceuticals. New York, NY: $\mathrm{MSCl}$ and Standard and Poor's, 1999. Accessed at http://www.msci.com/products/indices/sector/gics/, May 2, 2012.

Bloomberg LP, Accessed at www.bloomberg.com, May 2, 2012. 


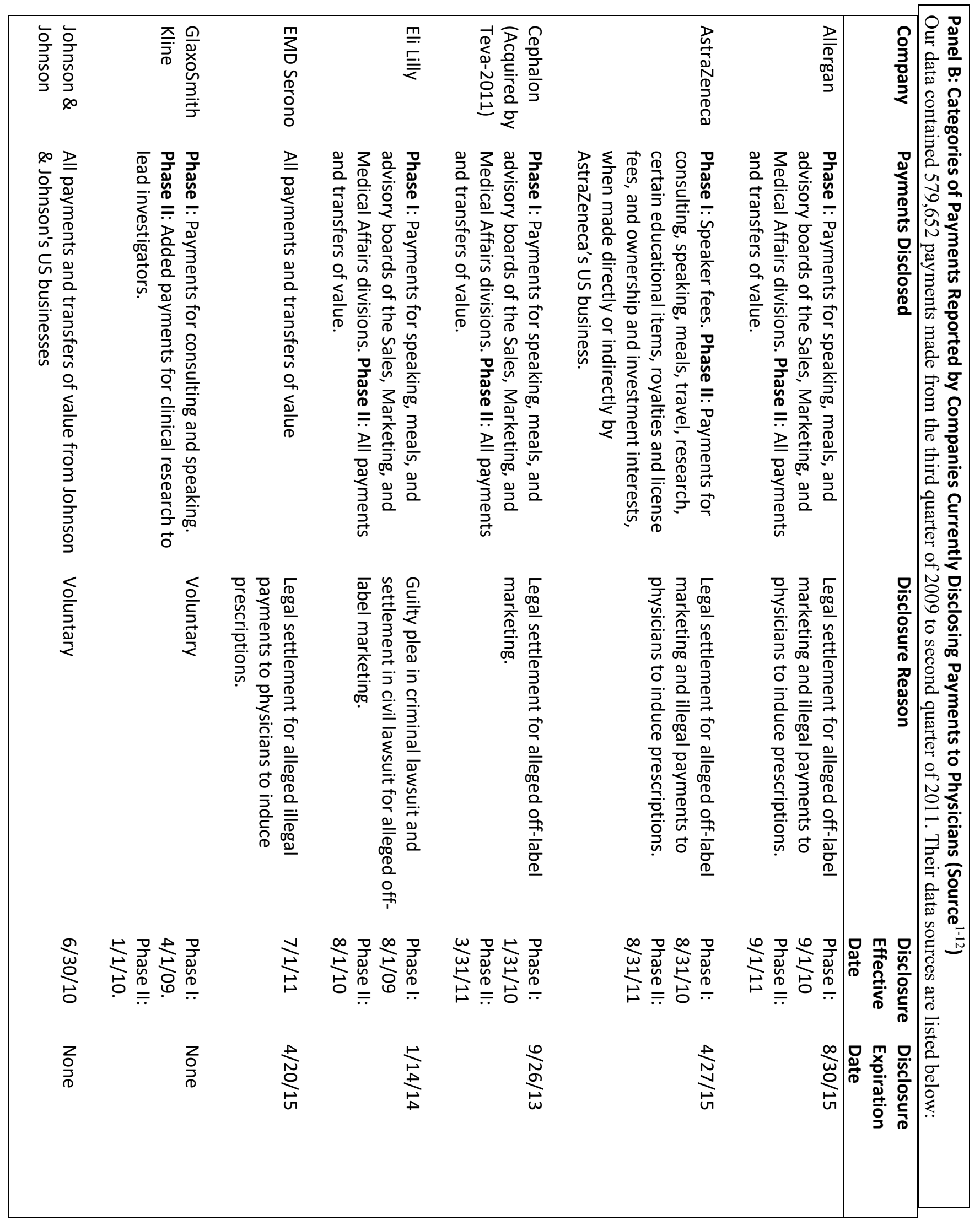



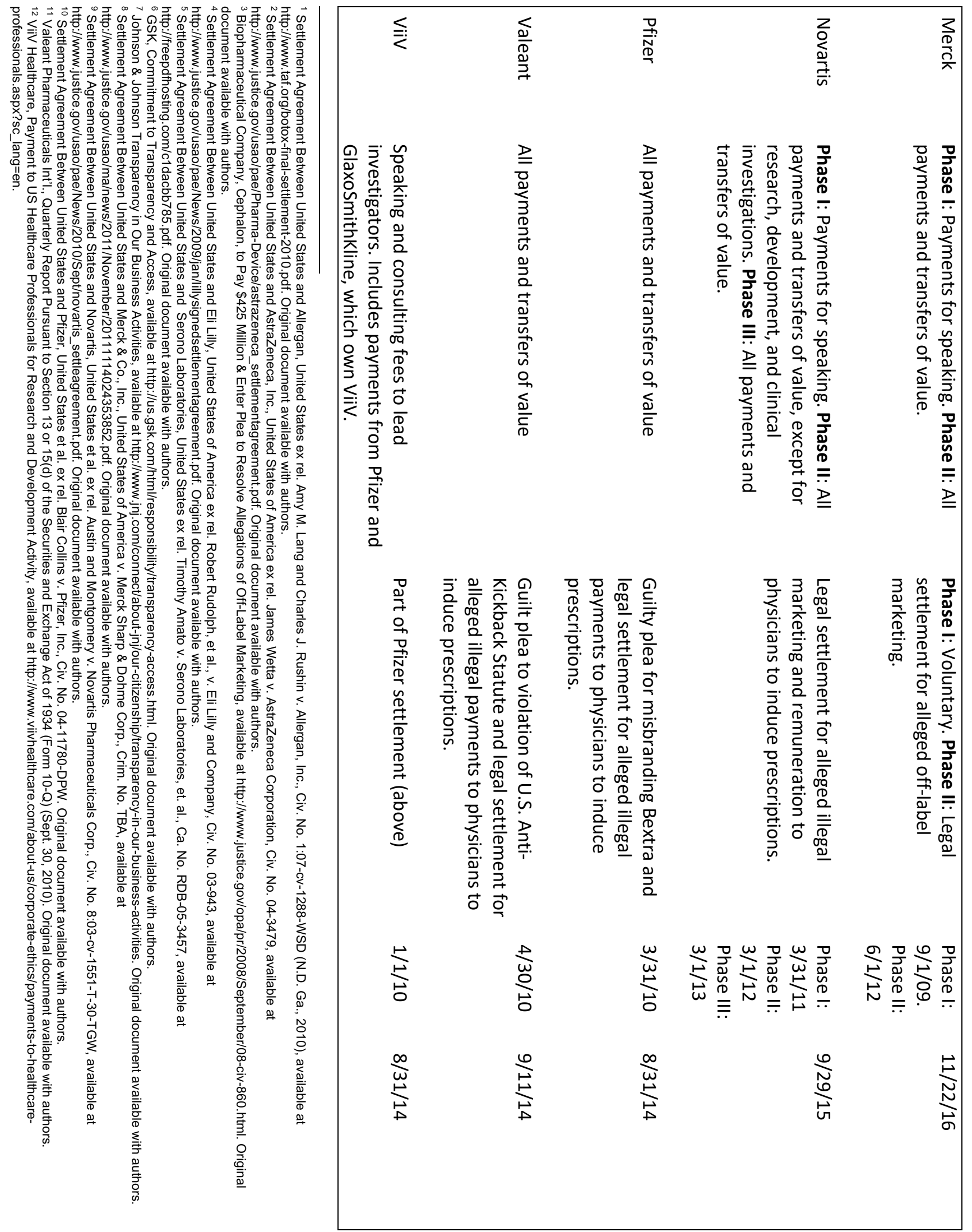
ONLINE PUBLICATION 


\section{Appendix 1 Panel C: Validation of ProPublica Data with Data Obtained Directly from One Pharmaceutical Company, for One Year}

ProPublica assembled data on payments to physicians from 12 pharmaceutical companies, between the third quarter of 2009 and fourth quarter of 2011. This compilation was important because historical data are not easily obtainable from all pharmaceutical companies directly. For example, some companies remove data from their website at the end of each quarter or year.

To partially validate the quality of the ProPublica data, we compared it with data obtained directly from Eli Lilly, for payments made to physicians during 2010 . We found a match of $\geq 97.5 \%$ for the number of physicians and total amount of payments, in each category and overall. Similarly high match rates were found for Astrazeneca payments made in 2010, GlaxoSmithKline payments made in 2009 Quarters 2 to 4, Johnson \& Johnson payments made in 2010, Merck payments made from 2009 Quarter 3 to 2010 Quarter 4, Valeant payments made in 2010 Quarters 1 to 3, and Viiv payments made in 2010. Other data were not reported in a quarterly or yearly time frame available for comparison.

ProPublica data for payments from Eli Lilly during 2010

\begin{tabular}{|l|c|c|c|c|c|}
\hline & Speaking & Consulting & Travel & Other & Total \\
\hline Number of Physicians & 3,727 & 1,005 & 3,683 & 864 & 9,279 \\
\hline Total Amount (\$) & $61,477,547$ & $4,114,517$ & $5,205,539$ & $7,065,820$ & $77,863,092$ \\
\hline
\end{tabular}

Data obtained directly from Eli Lilly for payments during 2010

(Eli Lilly and Company. Physician Payment Registry. Q1-Q4 2010 Lilly Faculty Registry. Accessed at http://www.lillyphysicianpaymentregistry.com/Registry/Archives, August 30, 2012)

\begin{tabular}{|l|c|c|c|c|c|}
\hline & Speaking & Consulting & Travel & Other & Total \\
\hline Number of Physicians & 3,743 & 1,016 & 3,701 & 867 & 9,327 \\
\hline Total Amount $(\$)$ & $61,925,592$ & $4,218,849$ & $5,232,081$ & $7,092,908$ & $78,469,430$ \\
\hline
\end{tabular}

ProPublica data / Data obtained directly from Eli Lilly for payments during 2010

\begin{tabular}{|l|c|c|c|c|c|}
\hline & Speaking & Consulting & Travel & Other & Total \\
\hline Number of Physicians & $99.6 \%$ & $98.9 \%$ & $99.5 \%$ & $99.7 \%$ & $99.5 \%$ \\
\hline Total Amount (\$) & $99.3 \%$ & $97.5 \%$ & $99.5 \%$ & $99.6 \%$ & $99.2 \%$ \\
\hline
\end{tabular}

Appendix 2. Description of State-level Variables Used as Controls in Regression Analysis 


\section{Real Income Per Capita (\$)}

Definition: Household income, 2010 / Consumer Price Index [an adjustment for inflation since 2001]

Source: U.S. Department of Commerce, Bureau of Economic Analysis

Rationale: Wealthier people may be more able afford prescription drugs but have fewer health problems (decreasing their need to purchase prescription drugs). Both factors may influence the interest of pharmaceutical companies in associating with physicians in these states.

\section{Average Physician Wage (\$)}

Definition: Average physician and surgeon wage, 2010

Source: U.S. Department of Labor, Bureau of Labor Statistics, Occupational and Employment Statistics, Occupational Employment and Wages, 29-1069 Physicians and Surgeons, All Other

Rationale: Physicians earning a higher income may have less need to supplement income through payments from pharmaceutical companies.

\section{Cost of Living Index}

Definition: Consumer price index in state, 2010

Source: U.S. Department of Labor, Bureau of Labor Statistics

Rationale: Physicians in states with a higher cost of living may need extra income (e.g., payments from pharmaceutical companies) to meet their expenses.

\section{Population $<18$ y $(\%)$}

Definition: Population aged $<18$ years / Total population, 2010

Source: U.S. Census Bureau, Current Population Survey

Rationale: Special considerations may be taken into account when prescribing medications for children (differential safety, dosage, duration, etc.). These issues may affect the interest of pharmaceutical companies in associating with physicians in states with a large proportion of children. 


\section{Population $\geq 65$ y $(\%)$}

Definition: Population aged $\geq 65$ years / Total population, 2010

Source: U.S. Census Bureau, Current Population Survey

Rationale: States with a large elderly population may have a bigger market share for prescription drugs, increasing the interest of pharmaceutical companies to associate with physicians in these states.

\section{$\geq$ High School Education (\%)}

Definition: Population with at least a high school education / Total population, 2010

Source: U.S. Census Bureau, Current Population Survey

Rationale: More educated persons may have a higher income, increasing their ability to afford prescription drugs. On the other hand, more educated persons may have fewer health problems, decreasing their need to purchase prescription drugs. Both factors may influence the interest of pharmaceutical companies in associating with physicians in these states.

\section{Health Insurance (\%)}

Definition: Population aged 18-64 years with health insurance / Total population 18-64 years, 2010 Source: U.S. Census Bureau, Current Population Survey

Rationale: Individuals with health insurance are more likely to be able to afford prescription medications, increasing the interest of pharmaceutical companies to associate with physicians in these states.

\section{Number of Retail Prescriptions Filled at Pharmacies (Person/Year)}

Definition: Total number of prescription drugs filled at retail pharmacies in 2011 / Population in 2011.

Source: The Kaiser Family Foundation, statehealthfacts.org. Retail Prescription Drugs Filled at

Pharmacies (Annual per Capita), 2011. Data Source: SDI Health, L.L.C.: Special Data Request, 2012 and

Calculations based on U.S. Census Bureau, 2011 Population Estimates,

http://www.census.gov/popest/data/index.html.

Rationale: Pharmaceutical companies may be more interested in associating with physicians in states with 
a bigger prescription drug market size.

Additional comments: Kaiser Family Foundation notes that prescription data are based on IMS's Vector

One ${ }^{\circledR}$ database which collects data from a panel of retail pharmacies, third party payers, and data providers. "Retail pharmacies" include independent pharmacies, chain pharmacies, food stores, and mass merchandisers, and exclude prescriptions filled by mail order; includes both brand name and generic drugs; and may include a small portion of over-the-counter medications and drugs transferred to different containers solely for distribution purposes.

\section{Population Density (Thousands/Square Mile)}

Definition: Total population (thousands), 2010 / Land area of state (square miles)

Source: U.S. Census Bureau, Current Population Survey and Statistical Abstract of the United States

Rationale: In densely populated areas, it may be easier for one physician to influence other physicians (for example, through more interaction with other physicians on a regular basis, whether casual or through well-attended speaking engagements). This may increase the interest of pharmaceutical companies in associating with physicians in more densely populated states.

\section{Number of Physicians with Active Licenses}

Definition: Number of physicians with active licenses, 2009-2010

Source: American Medical Association

Rationale: The amount that pharmaceutical companies are willing to pay physicians may be inversely associated with companies' ability to find another physician with similar qualifications. For example, if a pharmaceutical company can only locate one physician in a state with particular qualifications, then it may be willing to pay that physician $\$ 250$. But if a pharmaceutical company can locate five similar physicians, then it may only be willing to pay that physician $\$ 100$.

Additional comments: May include physicians who do not regularly practice medicine, such as those with primarily research or administrative responsibilities. 


\section{Number of Nurses with Active Licenses}

Definition: Number of nurses with active licenses, 2010

Source: American Hospital Association

Rationale: Disclosure data may occasionally contain payments made to nurses. Otherwise similar rationale to the number of physicians with active licenses.

Table 2 also presents summary statistics for these independent variables. States with strong disclosure laws, weak disclosure laws, and no disclosure laws are not observably different on most demographic characteristics. The exceptions are population density, number of active physicians, and number of active nurses. States with strong disclosure laws have greater population density than states with no disclosure laws but less than states with weak disclosure laws. States with strong disclosure laws and no disclosure laws have similar numbers of active physicians and active nurses, while states with weak disclosure laws have more active physicians and nurses. 


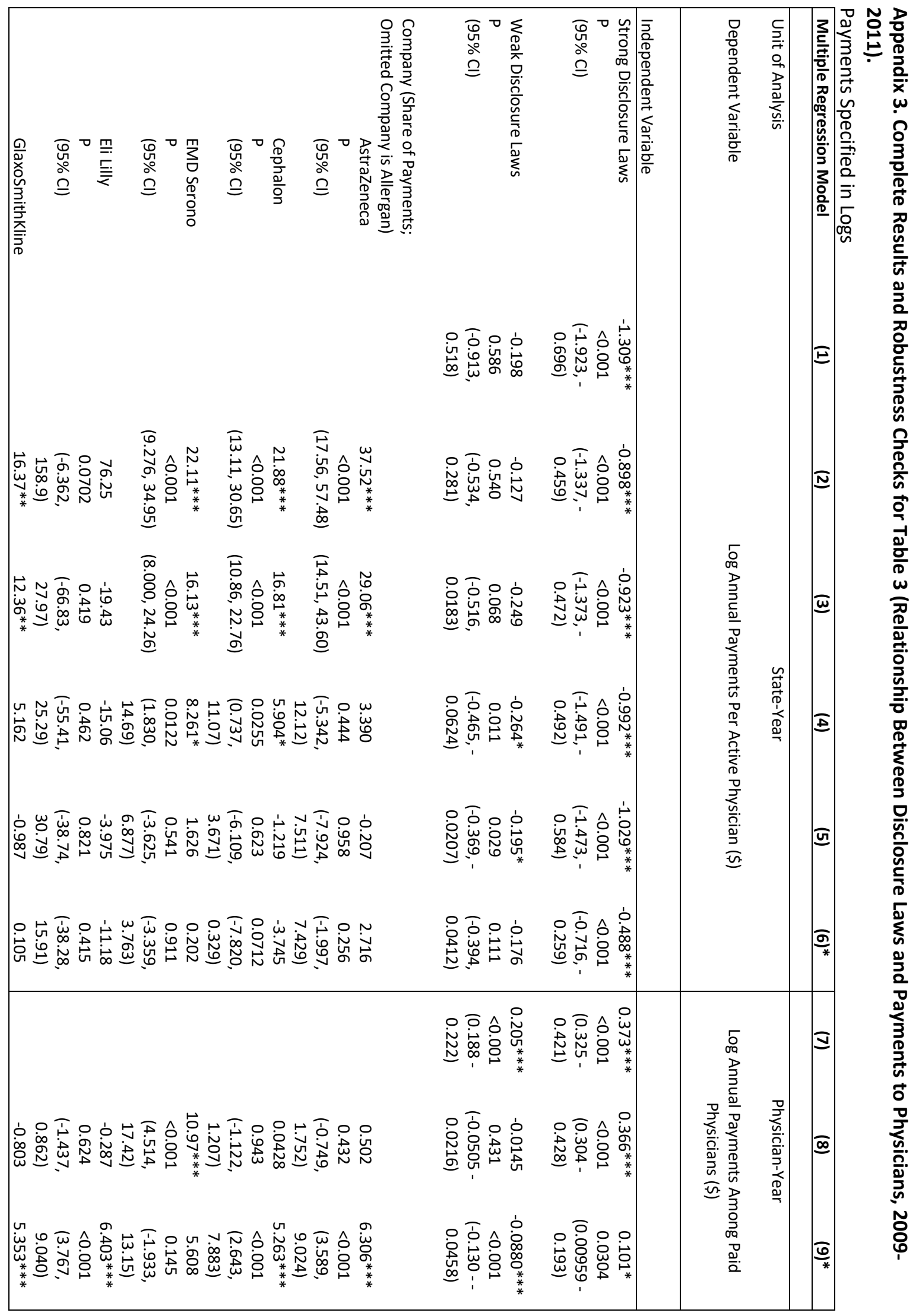




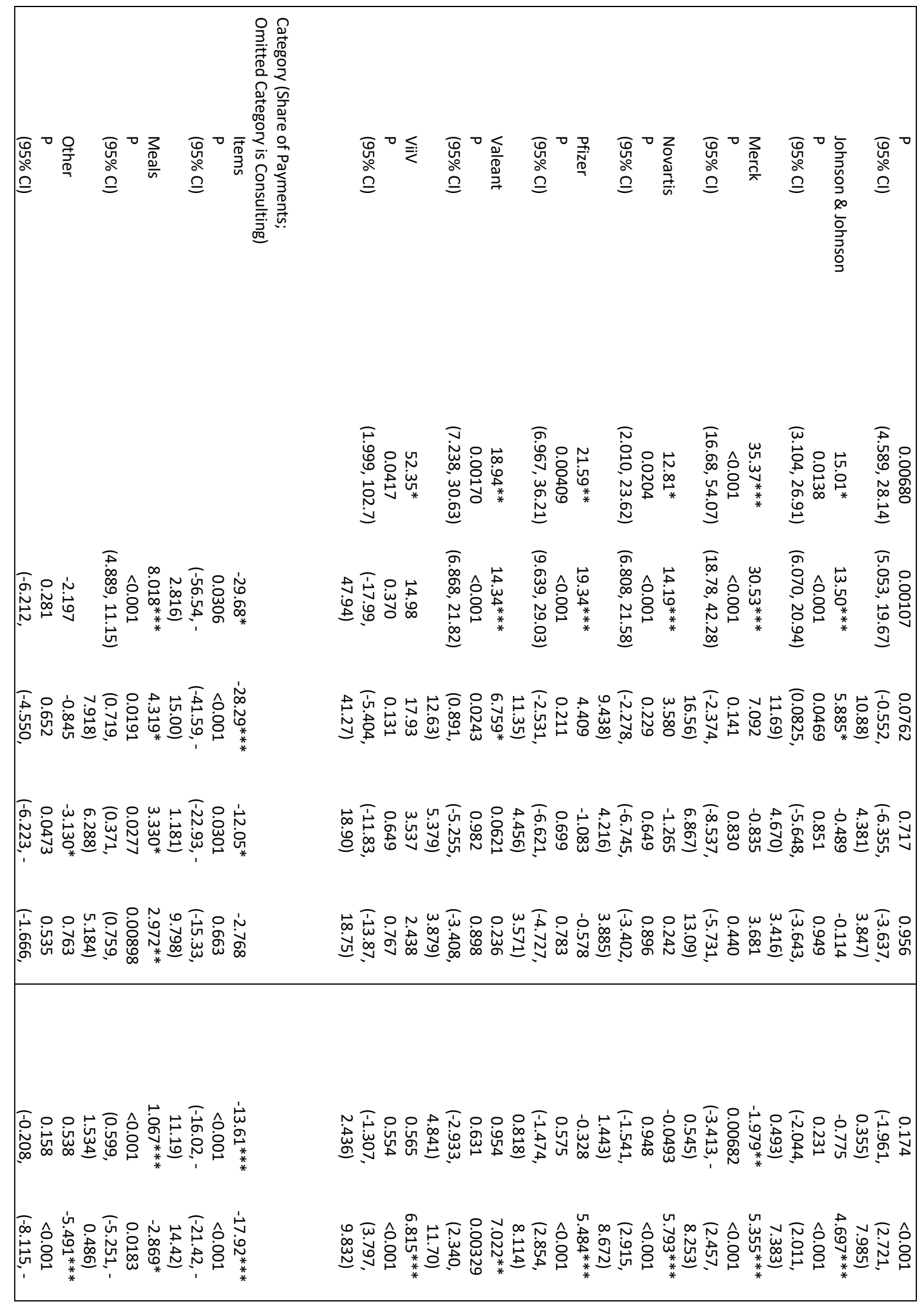




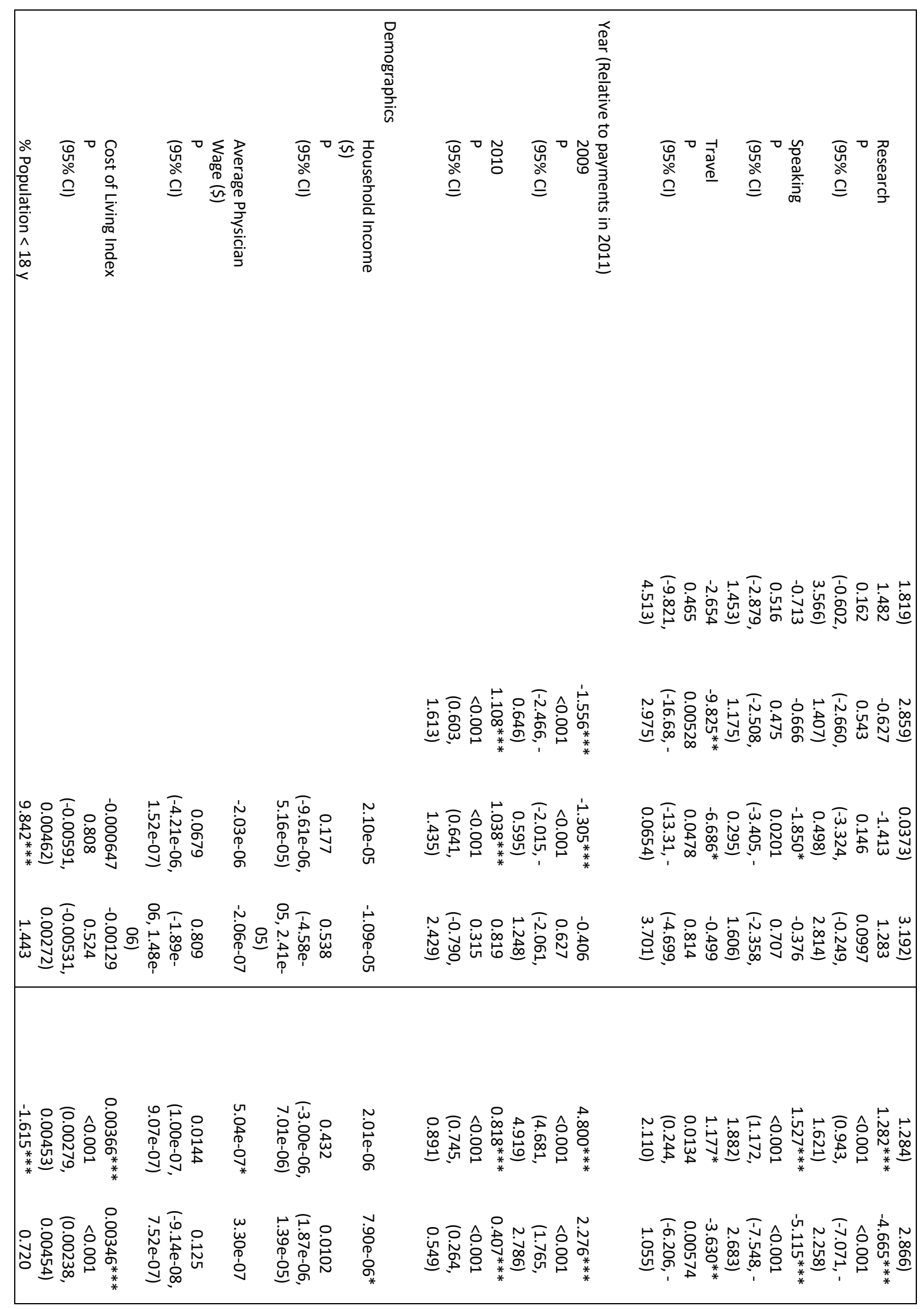




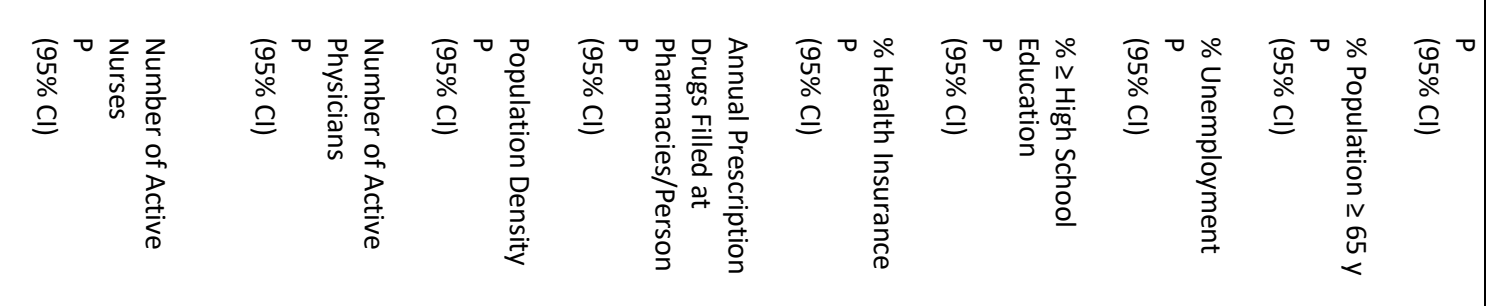

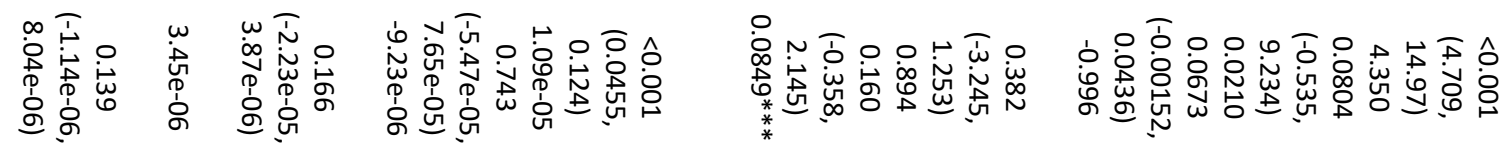

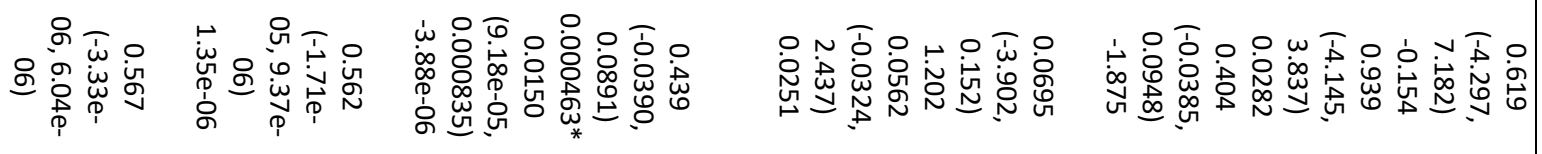

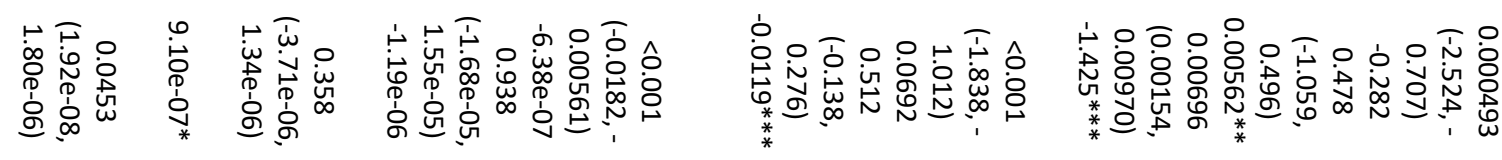

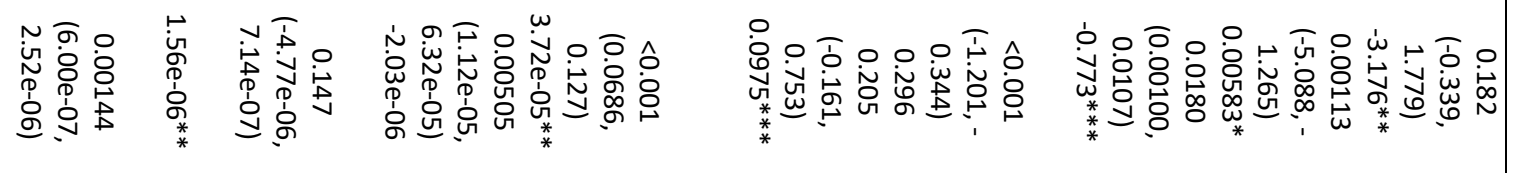




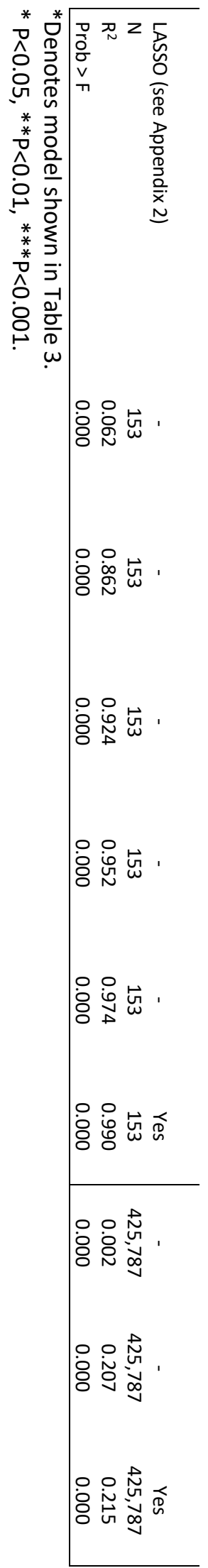




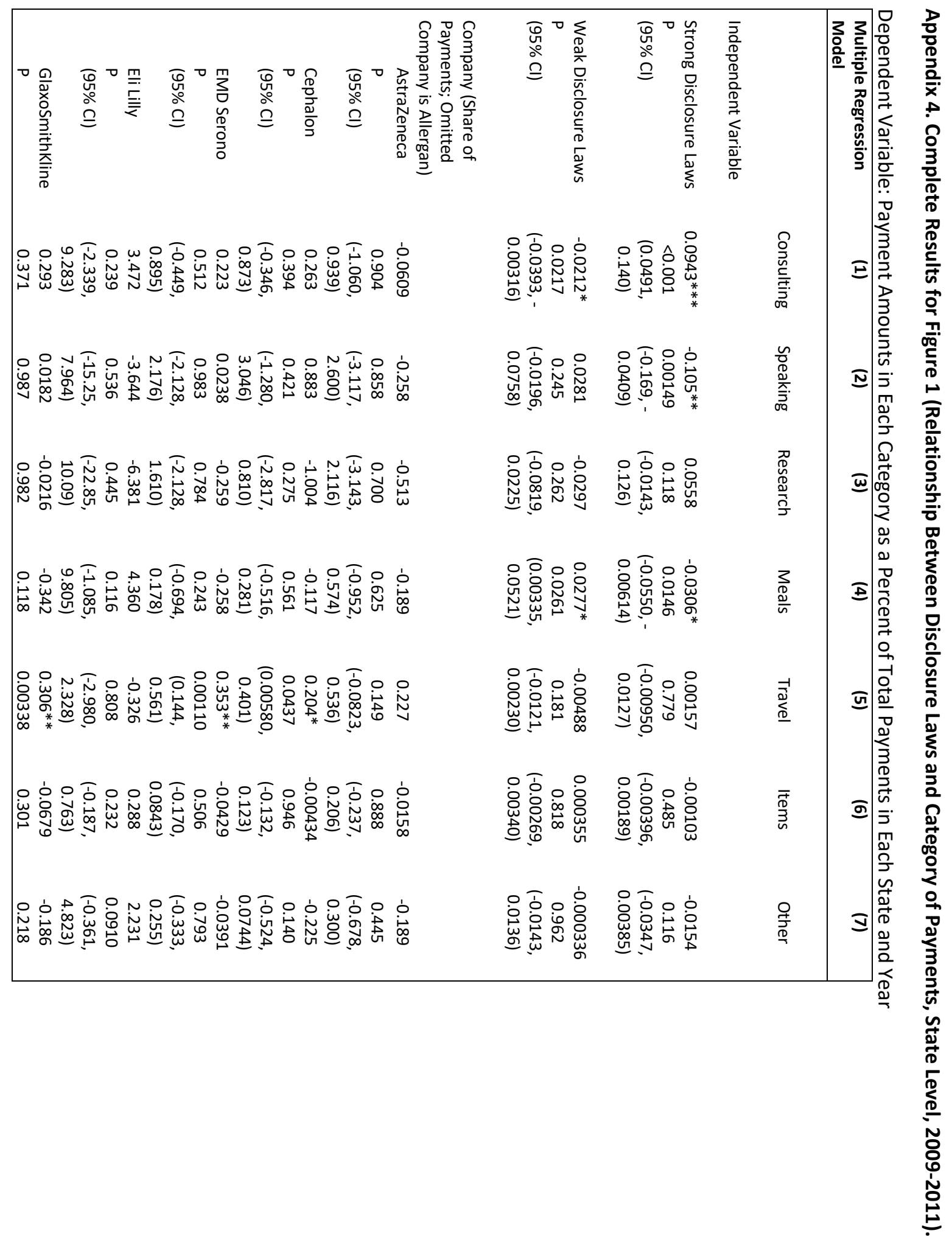




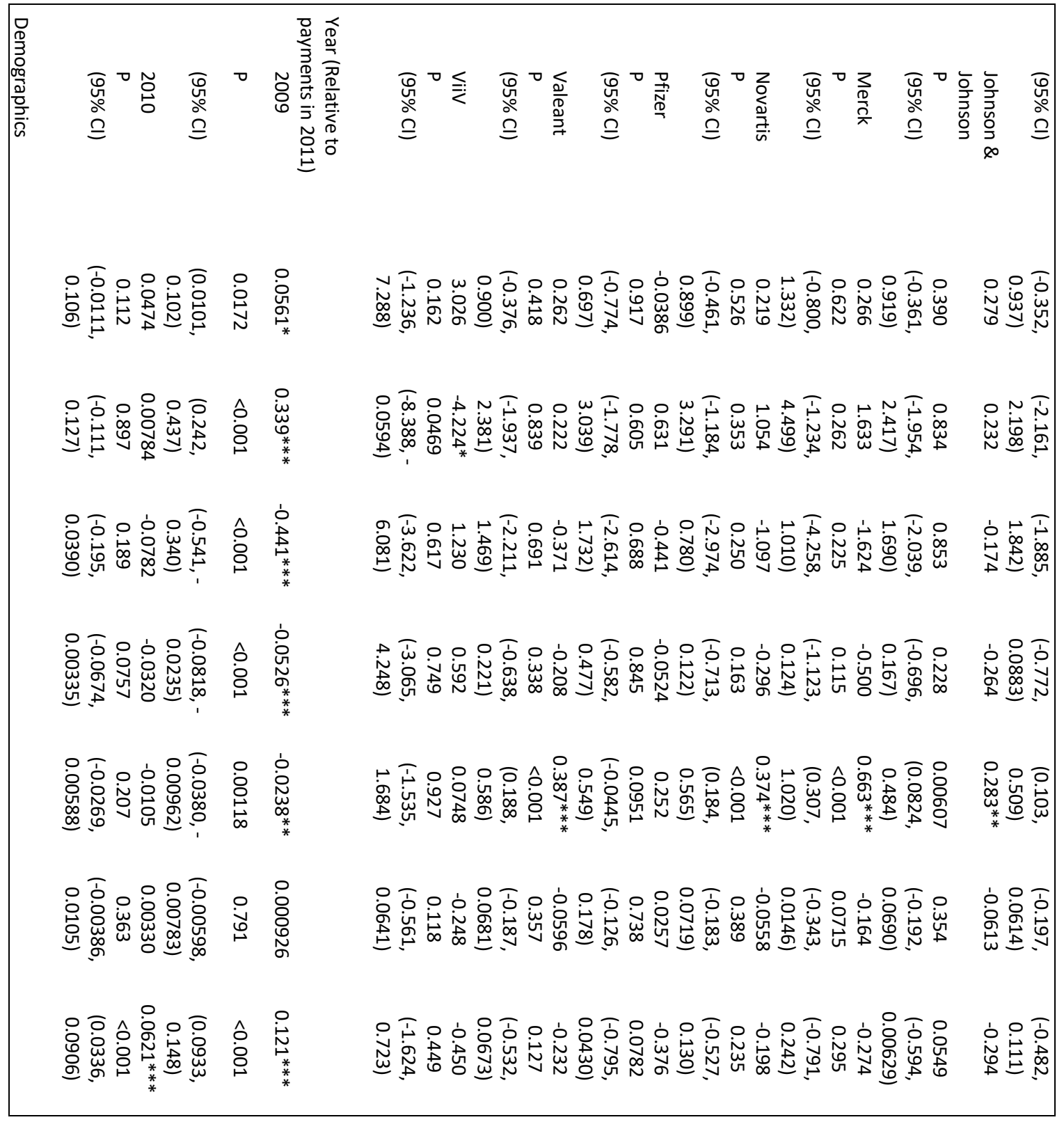




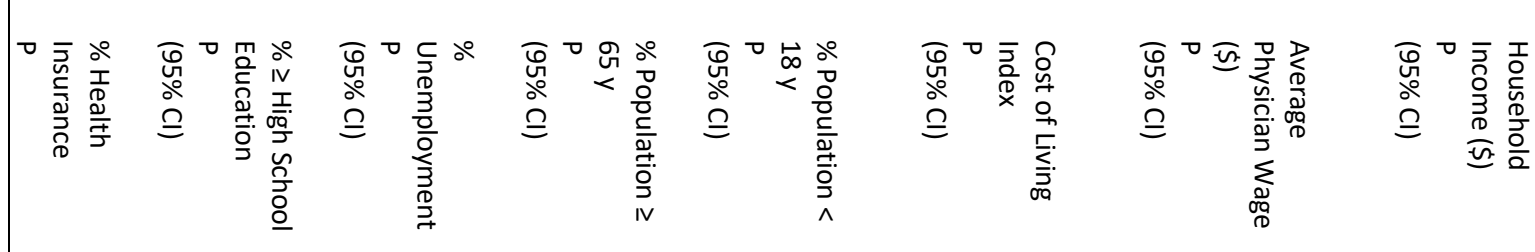

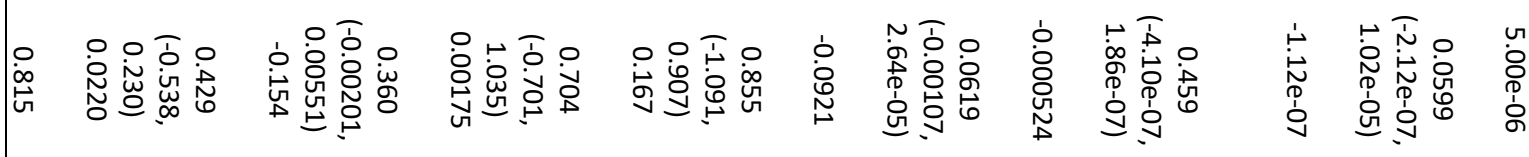

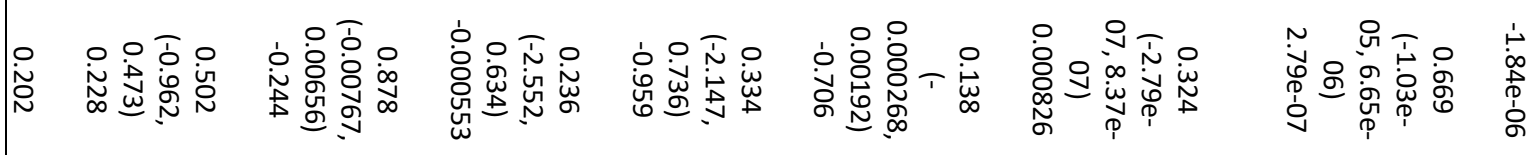

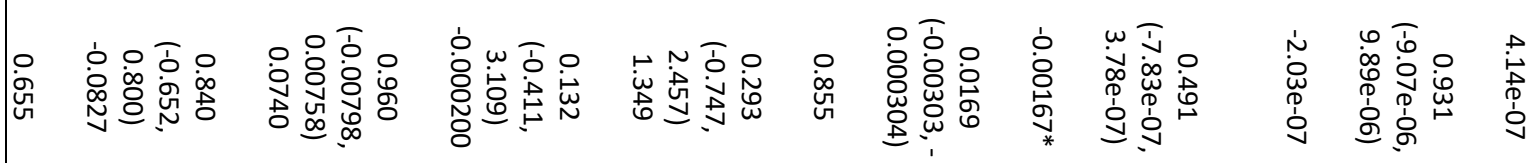

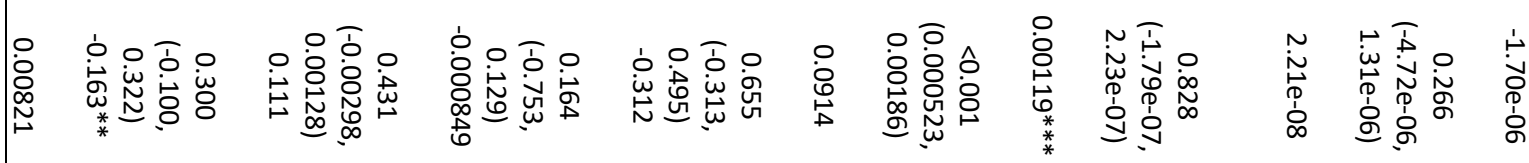

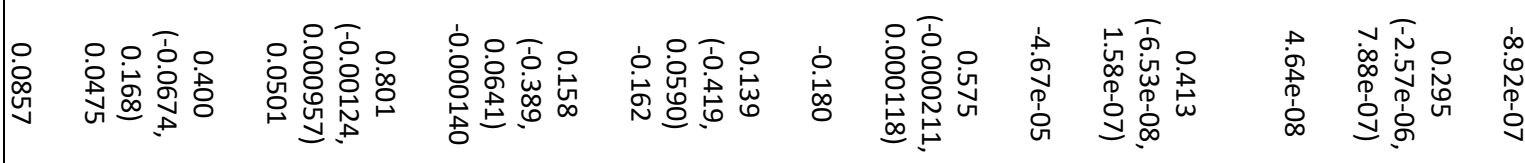

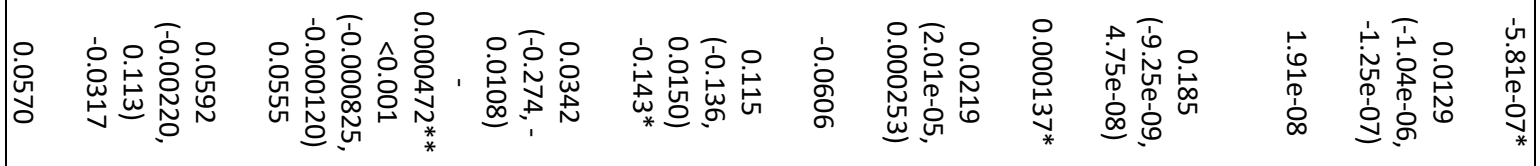

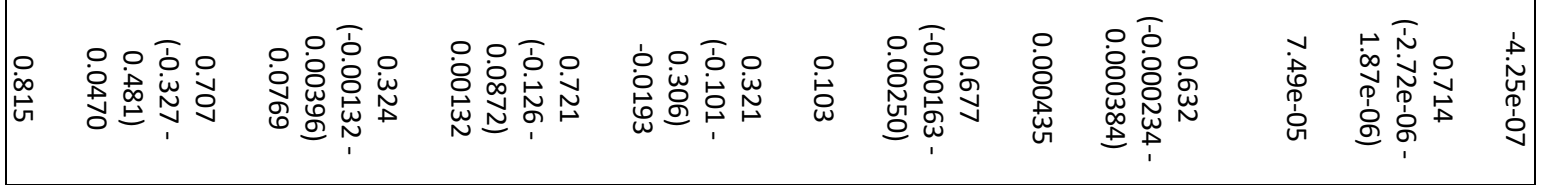




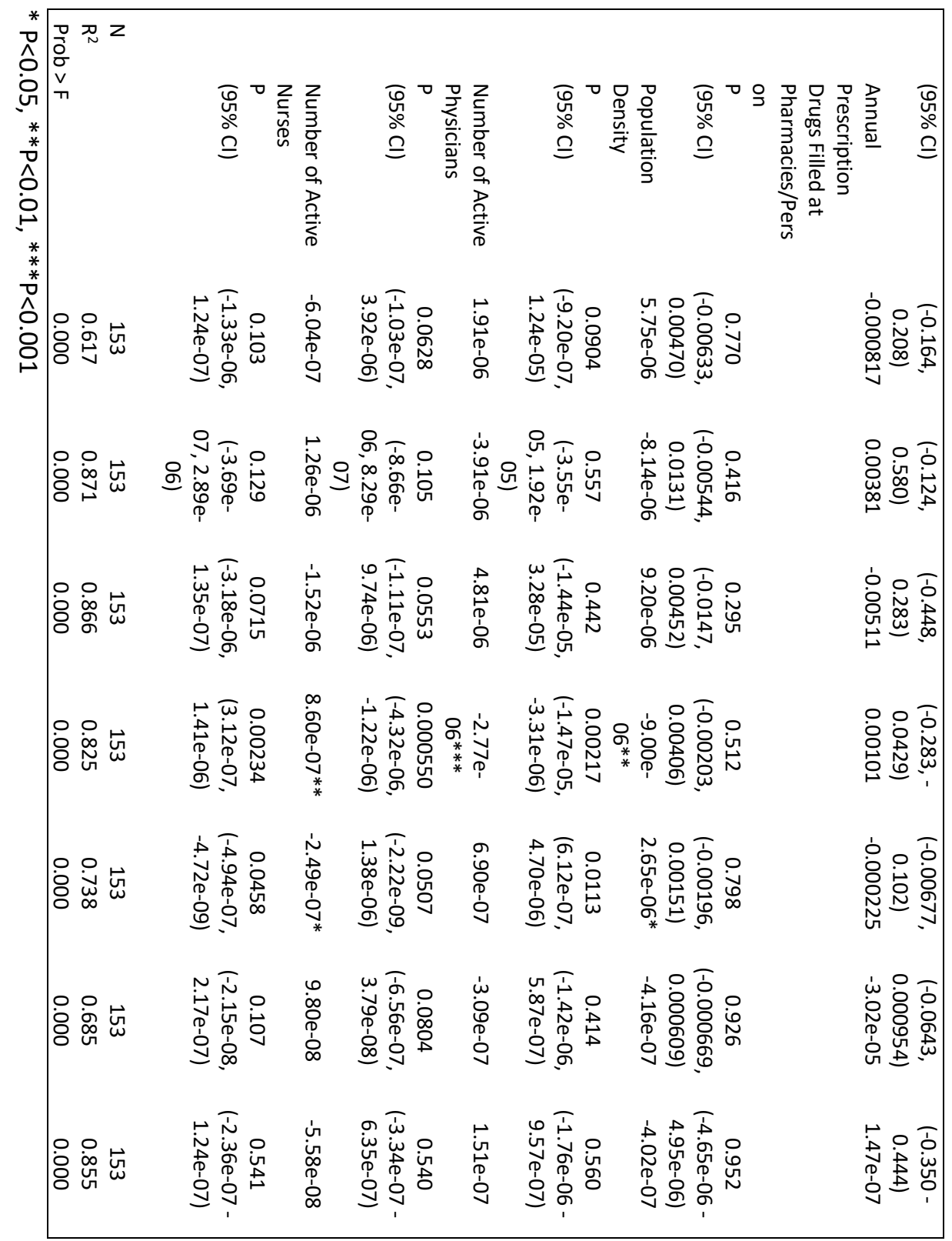




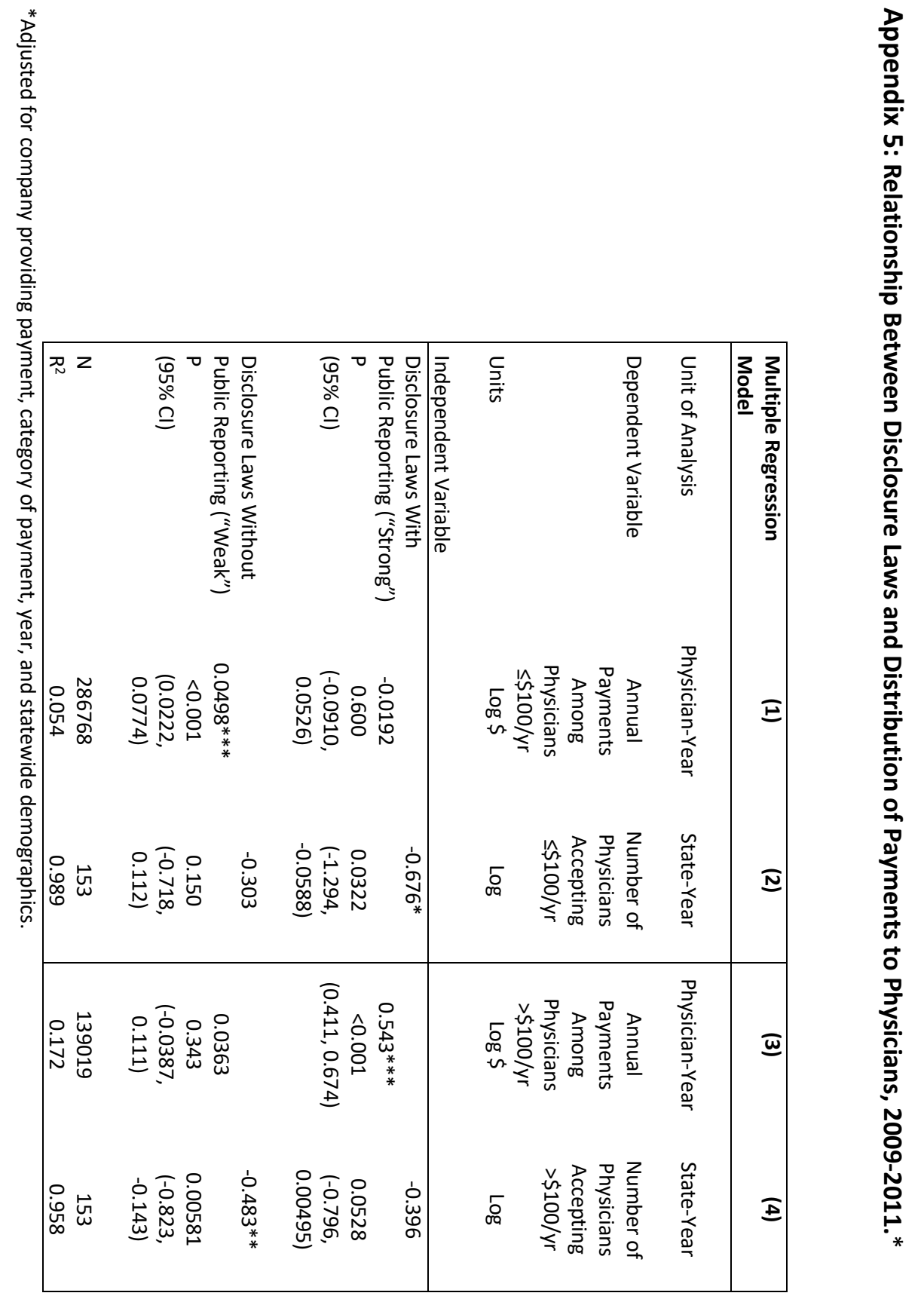




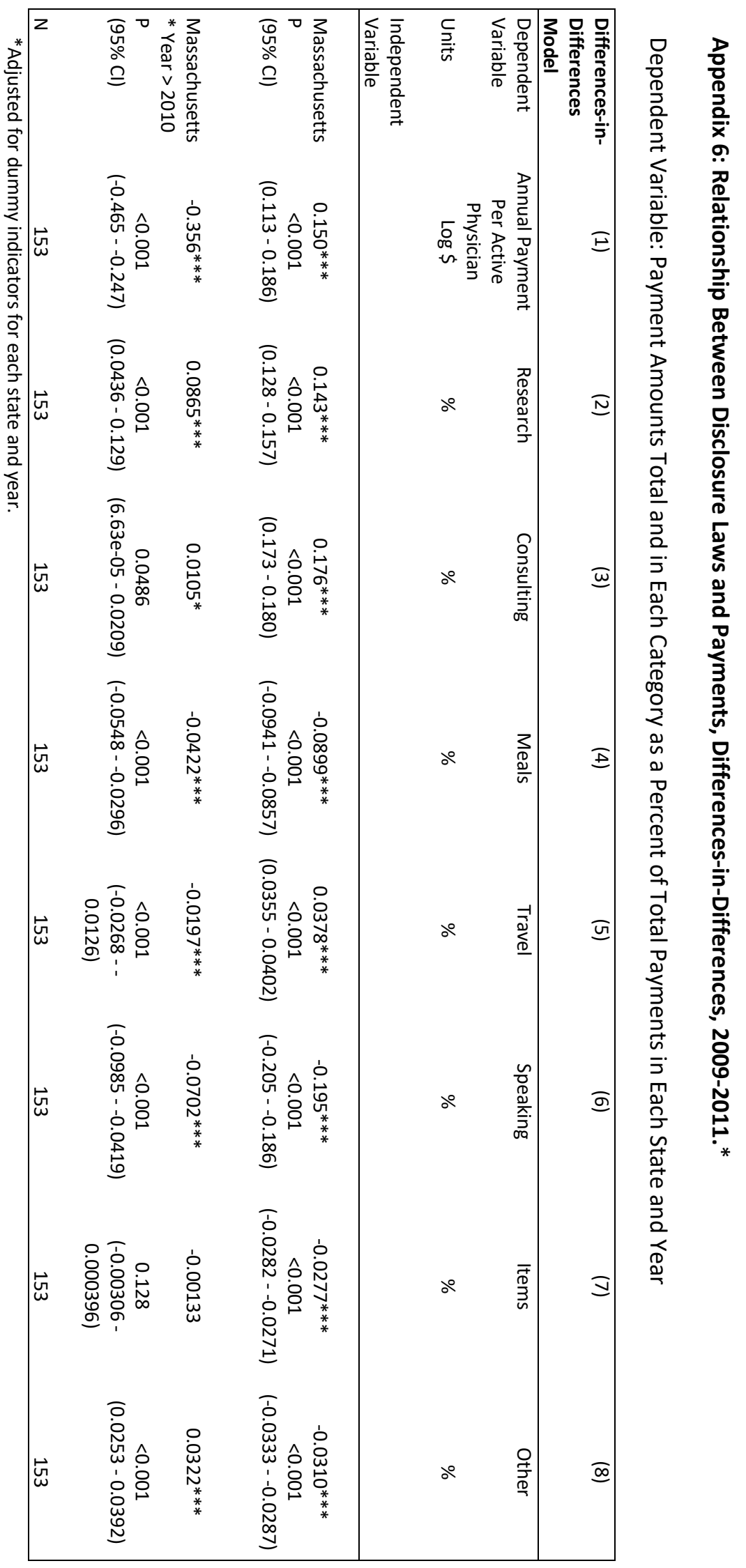


Appendix 7. Relationship Between Disclosure Laws and Payments to Physicians, 2009-2011.*

\begin{tabular}{|c|c|c|c|c|c|c|c|}
\hline Model & (1) & (2) & (3) & (4) & (5) & (6) & (7) \\
\hline & & & & & \multicolumn{3}{|c|}{$\begin{array}{c}\text { \{ Difference in Payments Between MA and All Other } \\
\text { States, Before and After Public Release of MA } \\
\text { Payments }\}\end{array}$} \\
\hline Unit of Analysis & State-Year & $\begin{array}{l}\text { Physician- } \\
\text { Year }\end{array}$ & $\begin{array}{l}\text { Physician- } \\
\text { Year }\end{array}$ & $\begin{array}{l}\text { Physician- } \\
\text { Year }\end{array}$ & State-Year & Physician-Year & Physician-Year \\
\hline Dependent Variable & $\begin{array}{l}\text { Log Annual } \\
\text { Payments } \\
\text { Per Active } \\
\text { Physician }\end{array}$ & $\begin{array}{l}\text { Log Annual } \\
\text { Payments } \\
\text { Among Paid } \\
\text { Physicians }\end{array}$ & $\begin{array}{l}\text { Log Annual } \\
\text { Payments } \\
\text { Among } \\
\text { Physicians } \\
\text { Who } \\
\text { Accepted } \\
>\$ 100\end{array}$ & $\begin{array}{l}\text { Log Annual } \\
\text { Payments } \\
\text { Among } \\
\text { Physicians } \\
\text { Who } \\
\text { Accepted } \\
\leq \$ 100^{* *}\end{array}$ & $\begin{array}{l}\text { Log Annual } \\
\text { Payments Per } \\
\text { Active Physician }\end{array}$ & $\begin{array}{l}\text { Log Annual } \\
\text { Payments } \\
\text { Among } \\
\text { Physicians } \\
\text { Who Accepted } \\
>\$ 100\end{array}$ & $\begin{array}{l}\text { Log Annual } \\
\text { Payments } \\
\text { Among } \\
\text { Physicians Who } \\
\text { Accepted } \\
\leq \$ 100^{* *}\end{array}$ \\
\hline \multicolumn{8}{|l|}{ Independent Variable } \\
\hline $\begin{array}{l}\text { Disclosure Laws With } \\
\text { Public Reporting ("Strong”) }\end{array}$ & $-0.488 * * *$ & 0.101 & $1.785^{*}$ & $-0.255^{* * *}$ & & & \\
\hline $\begin{array}{l}P \\
(95 \% \mathrm{Cl})\end{array}$ & $\begin{array}{l}<0.001 \\
(-0.698 \\
-0.277)\end{array}$ & $\begin{array}{c}0.188 \\
(-0.0512 \\
0.254)\end{array}$ & $\begin{array}{l}0.0236 \\
(0.239 \\
3.331)\end{array}$ & $\begin{array}{l}<0.001 \\
(-0.301 \\
-0.208)\end{array}$ & & & \\
\hline $\begin{array}{l}\text { Disclosure Laws Without } \\
\text { Public Reporting (“Weak") }\end{array}$ & -0.176 & -0.0880 & 0.506 & -0.0614 & & & \\
\hline$P$ & 0.104 & 0.0551 & 0.386 & 0.321 & & & \\
\hline$(95 \% \mathrm{Cl})$ & $\begin{array}{l}(-1.254 \\
8.852)\end{array}$ & $\begin{array}{l}(-0.178 \\
0.00198)\end{array}$ & $\begin{array}{c}(-0.638, \\
1.650)\end{array}$ & $\begin{array}{l}(-0.183 \\
0.0598)\end{array}$ & & & \\
\hline $\begin{array}{l}\text { Massachusetts x After } \\
\text { Public Release in MA }\end{array}$ & & & & & $-0.356 * * *$ & $8.503 * * *$ & $-0.0685^{* * *}$ \\
\hline $\begin{array}{l}\mathrm{P} \\
(95 \% \mathrm{Cl})\end{array}$ & & & & & $\begin{array}{c}<0.001 \\
(-0.465,-0.247)\end{array}$ & $\begin{array}{c}<0.001 \\
(5.611,11.39)\end{array}$ & $\begin{array}{l}<0.001 \\
(-0.0841 \\
-0.0530)\end{array}$ \\
\hline $\begin{array}{l}\mathrm{N} \\
\mathrm{R}^{2}\end{array}$ & $\begin{array}{l}153 \\
0.99 \\
\end{array}$ & $\begin{array}{c}425,797 \\
0.215 \\
\end{array}$ & 139,019 & $2,257,059$ & $\begin{array}{c}153 \\
0.972 \\
\end{array}$ & 141,736 & $2,257,059$ \\
\hline
\end{tabular}

*Adjusted for company providing payment, category of payment, year, and statewide demographics. Demographics are household income, average physician wage, cost of living, $\%$ population $<18, \%$ population $\geq 65, \%$ unemployment, $\% \geq$ high school education, \% health insurance, annual prescription drugs filled at pharmacies/person, population density, number of active physicians, and number of active nurses. Full results displayed in Appendix 3 . Additional LASSO controls in Appendix 8. Standard errors clustered at the state level. Columns 3, 4, 6, and 7 implement truncated regressions.

$* *$ Included a zero for physicians who accepted no payments. 
Appendix $8 \quad$ LASSO variables

\begin{tabular}{|l|l|}
\hline Annual Physician Mean Wage & Number of Paid Physicians \\
\hline \% Unemployment & Number of Physicians \\
\hline Physicians Per Capita & Number of Nurses \\
\hline Population & Land Area \\
\hline Population Density & Percent Under 18 \\
\hline Percent Over 65 & Cost of Living Index \\
\hline Prescribed Drugs Per Capita & Adoption Rate \\
\hline Percent of Women Aged 25-29 & Percent of Women Aged 30-34 \\
\hline Percent Hispanic & Percent Non-Hispanic \\
\hline Percent Insured & Percent of Women Working \\
\hline High School Completion & Income Per Capita \\
\hline Percent in Large Firms & Raw Consumer Price Index \\
\hline Consumer Price Index & Real Income Per Capita \\
\hline$\%$ Payments from each Company by Value and by Count & \% Payments in each Payment Category by Value and by Count \\
\hline Year Fixed Effects & All two-way interactions between any of these variables \\
\hline
\end{tabular}

Variables selected by LASSO for state-level regressions

\begin{tabular}{|l|l|}
\hline $\begin{array}{l}\text { Number of Paid Physicians * \% Payments by Count for } \\
\text { Cephalon }\end{array}$ & Unemployment Rate * \% Payments by Count from Pfizer \\
\hline Number of Paid Physicians * \% Payments by Value for Items & $\begin{array}{l}\text { \% Payments by Count from Cephalon * \% Payments by Count } \\
\text { from Pfizer }\end{array}$ \\
\hline Percent Under 18 * \% Payments by Count for Meals & $\begin{array}{l}\text { \% Payments by Count from Eli Lilly * \% Payments by Value for } \\
\text { Speaking }\end{array}$ \\
\hline Cost of Living Index * \% Payments by Count for Consulting & $\begin{array}{l}\text { \% Payments by Count from Pfizer * \% Payments by Count for } \\
\text { Meals }\end{array}$ \\
\hline $\begin{array}{l}\text { Prescribed Drugs Per Capita * Percent of Women Aged 25- } \\
29\end{array}$ & $\begin{array}{l}\text { \% Payments by Count for Meals * \% Payments by Value for } \\
\text { Speaking }\end{array}$ \\
\hline $\begin{array}{l}\text { Prescribed Drugs Per Capita * \% Payments by Value from } \\
\text { AstraZeneca }\end{array}$ & \begin{tabular}{l} 
\% Payments by Count for Meals * Year 2010 Fixed Effect \\
\hline $\begin{array}{l}\text { Prescribed Drugs Per Capita * \% Payments by Value from } \\
\text { Johnson \& Johnson }\end{array}$
\end{tabular} \\
\hline $\begin{array}{l}\text { Prescribed Drugs Per Capita * \% Payments by Count for } \\
\text { Meals }\end{array}$ & Employment Rate * \% Payments by Value for Consulting \\
\hline $\begin{array}{l}\text { Annual Physician Mean Wage * \% Payments by Count for } \\
\text { Speaking }\end{array}$ & Physicians Per Capita * \% Payments by Count for Research \\
\hline Percent in Large Firms * \% Payments by Count from Pfizer & Population Density * Population Density \\
\hline
\end{tabular}

Variables selected by LASSO for paid physician-level regressions

\begin{tabular}{|l|l|}
\hline \% Payments by Count for Speaking & Cost of Living Index * \% Payments by Count for Speaking \\
\hline Physicians Per Capita * \% Payments by Count for Other & Drugs Per Capita * \% Payments by Count for Meals \\
\hline Percent Over 65 * \% Payments by Count for Meals & Drugs Per Capita * \% Payments by Count for Other \\
\hline Cost of Living Index * \% Payments by Count for Consulting & Drugs Per Capita * Year 2011 Fixed Effect \\
\hline Adoption Rate * \% Payments by Count for Consulting & Percent Insured * \% Payments by Count for Meals \\
\hline Percent in Large Firms * \% Payments by Count for Meals & \% Unemployment * \% Payments by Count from Merck \\
\hline$\%$ Unemployment * \% Payments by Count for Consulting & \% Unemployment * \% Payments by Count for Speaking \\
\hline $\begin{array}{l}\text { \% Payments by Count from Cephalon * \% Payments by } \\
\text { Count for Meals }\end{array}$ & $\begin{array}{l}\text { \% Payments by Value from Eli Lilly * \% Payments by Count for } \\
\text { Meals }\end{array}$ \\
\hline Physicians Per Capita * \% Payments by Value for Consulting & Drugs Per Capita * \% Payments by Value for Consulting \\
\hline $\begin{array}{l}\text { Number of Paid Physicians * \% Payments by Value from } \\
\text { Valeant }\end{array}$ & \\
\hline
\end{tabular}

Variables selected by LASSO for physician-level regressions

Real Income Per Capita * Year 2009 Fixed Effect

Drugs Per Capita * Percent Under 18

$\%$ Unemployment ${ }^{*}$ Year 2009 Fixed Effect

$\%$ Unemployment * Year 2010 Fixed Effect

$\%$ Unemployment * Number of Nurses

Drugs Per Capita * Year 2009 Fixed Effect

Drugs Per Capita * Year 2010 Fixed Effect 